\title{
NEUROPSYCHOPHARMACOLOGY REVIEWS Inflaming sex differences in mood disorders
}

\author{
Jennifer R. Rainville ${ }^{1}$ and Georgia E. Hodes $\mathbb{D D}^{1}$
}

\begin{abstract}
Men and women often experience different symptoms or rates of occurrence for a variety of mood disorders. Many of the symptoms of mood disorders overlap with autoimmune disorders, which also have a higher prevalence in women. There is a growing interest in exploring the immune system to provide biomarkers for diagnosis of mood disorders, along with new targets for developing treatments. This review examines known sex differences in the immune system and their relationship to mood disorders. We focus on immune alterations associated with unipolar depression, bipolar depression, and anxiety disorders. We describe work from both basic and clinical research examining potential immune mechanisms thought to contribute to stress susceptibility and associated mood disorders. We propose that sex and age are important, intertwined factors that need to be included in future experimental designs if we are going to harness the power of the immune system to develop a new wave of treatments for mood disorders.
\end{abstract}

Neuropsychopharmacology (2019) 44:184-199; https://doi.org/10.1038/s41386-018-0124-7

\section{INTRODUCTION}

There is an increasing understanding that mood disorders, such as depression and anxiety, alter the body as well as the brain. Immune function contributes to bio-phenotypes associated with these disorders and can be measured as potential biomarkers that may aid in diagnosing and treating mental illness. Mood and immune disorders have a higher prevalence in women (2-10 times depending upon the disorder) but most pre-clinical studies have used male animals to examine potential mechanisms [1, 2]. Clinical studies do include women but rarely examine sex or gender as a factor. When sex is included as a variable, subjects are often grouped across an age range of 18-65. This means that menopause or andropause are not taken into consideration, even given the extensive literature relating immune function to gonadal hormones [3-6]. This review will cover the current knowledge of sex differences in the immune system and the potential mechanisms through which they may contribute to sex differences in mood disorders.

\section{SEX DIFFERENCES: MOOD DISORDERS}

Mood disorders such as unipolar depression, generalized anxiety disorder, social anxiety disorders, and post-traumatic stress disorder (PTSD) are all more commonly diagnosed in women than men [7-12]. Symptoms and impairments associated with these disorders also vary by sex. Men reported that major depressive disorder (MDD) impaired their ability to work or study, including social and cognitive functioning, whereas women reported more social impairment [13-15]. Men presented with more symptoms of anger and addiction in response to MDD, along with low self-esteem, self-dislike, and cognitive effects [16]. Women presented with symptoms including anhedonia, alterations in sleep and feeding behavior, sadness, crying, somatization, hostility, feelings of worthlessness, and a higher incidence of comorbid anxiety [17-19]. Subtypes of depression differ by sex.
Women were diagnosed three times more often than men with atypical depression, defined as a higher prevalence of mood reactivity, paralysis, and increases in eating and sleeping [20]. Women had a higher incidence of depression with somatic symptoms, i.e., experiencing physical symptoms that cause distress [21], and anxious depression than men. Men had a higher incidence of comorbid substance use disorder [20].

Bipolar depression has even distribution of occurrence across the sexes [22]. Women have a higher incidence of diagnosis with bipolar 2 and hypomania than men [23-25], but this remains controversial $[26,27]$. Women were reported to undergo rapid cycling more often than men [28-30], in some but not all studies $[23,24]$. Female patients with bipolar depression had symptoms associated with atypical depression including changes in appetite, weight, and sleep [31,32]. More men were diagnosed more often with comorbid substance disorder, especially for alcohol [17, 26, 33]. Sex differences are also reported for comorbid anxiety disorders but are dependent upon the type of anxiety disorder. There was either no sex difference $[23,34]$ in comorbid obsessive-compulsive disorder (OCD) or potentially a higher expression in males than females [35]. Social phobia [34], and PTSD $[23,34,36]$, were more likely to occur in women diagnosed with bipolar disorder. There is evidence that gonadal hormones trigger episodes of bipolar disorder. Women diagnosed with bipolar disorder had a higher risk of a manic or depressive episode during periods of extreme hormonal fluctuations, such as menopause [37-39] or childbirth [40-42].

Women are more often diagnosed with anxiety disorder [4345], with the exception of OCD, which is diagnosed at equal rates in adulthood [46, 47], and has a higher incidence of early onset in male children [46]. Symptoms of a number of anxiety disorders differ between men and women, including social anxiety [48], generalized anxiety disorder [49] and OCD. Whereas PTSD does not differ in symptoms experienced by men and women [49], there are differences in the rate of occurrence with two times the

\footnotetext{
${ }^{1}$ Department of Neuroscience, Virginia Polytechnic Institute and State University, 1981 Kraft Drive, Blacksburg, VA 24060, USA
}

Correspondence: Georgia E. Hodes (ghodes@vt.edu)

Received: 7 March 2018 Revised: 7 June 2018 Accepted: 11 June 2018

Published online: 19 June 2018 
lifetime risk for women $[43,50,51]$, even when controlling for type of trauma [52-54]. Biomarkers for PTSD also differ by sex. Men experiencing PTSD or trauma had changes in hippocampal volume $[55,56]$. In women, but not men, a molecular biomarker and its related receptor's genetic polymorphism were predictive of an increased risk for PTSD [57]. Understanding the myriad ways that males and females with mood disorders differ and overlap in their biology will help us develop better screens and treatments for all genders.

\section{INFLAMMATION}

Inflammation is a complex response and that involves the release of a number of cellular signaling components into the blood or injured tissue in order to remove threat, restore homeostasis, resolve infection, and result in tissue repair $[58,59]$. Immediately after an insult occurs, there is an inflammatory response of the innate immune system that can last for hours after exposure [60]. This includes activation of attack/scavenger cells and humoral responses, such as release of complement and antimicrobial peptides. These innate components are genetically programmed in the germline, and have evolved to respond to common, but essential, pathogen structures [60]. The adaptive immune system responds slowly over days and weeks following an insult or exposure. The cellular components respond to self vs. non-self/or danger signals and release antibodies in response to specific antigens. The adaptive immune system is flexible and capable of recognizing and responding to virtually any foreign antigen [61]. Innate and adaptive immune responses cooperate to identify and eliminate infectious elements through the actions of leukocytes/ lymphocytes, the cells of the immune system (Box 1).

Immune cells communicate with and affect the behavior of other cells using cytokines. Levels of cytokines transiently spike owing to acute infection or injury but normally return to a low circulating baseline once the episode has passed. If the acute response fails to remove the threat, then chronic inflammation is activated. Chronic inflammation results in long-lasting alterations in the circulating levels of cytokines. Cytokines can be classified as pro-inflammatory when they trigger recruitment of leukocytes and induce phagocytosis, or anti-inflammatory when they suppress inflammation and increase healing [58, 59]. However, many cytokines have both pro- and anti-inflammatory properties and their role in inflammation can change depending on the amount of cytokine expressed, the length of time it is expressed, or which form of the receptor the cytokine activates [62]. New work is also

Box 1: cells of the peripheral immune system

Granulocytes. Include neutrophils, eosinophils, basophils, and mast cells. They are short-lived granulocytes that can infiltrate tissue, release cytokines, and toxins. They then scavenge debris and microbes. These cells are the first line of defense against a pathogen.

Monocytes/macrophages. Monocytes are the immature, pro-inflammatory state of macrophages, which are released into blood from the bone marrow. Macrophages are scavenger cells and vary by type of tissue that they inhabit. Monocytes and macrophages can be designated as polarized to M1 if they produce pro-inflammatory cytokines or $\mathrm{M} 2$ if they produce anti-inflammatory cytokines.

Natural killer (NK) cells. Originate from lymphoid progenitors but are a part of the innate immune response. They have the ability to target and kill tumors, bacteria, parasites, and cells infected with viruses.

Dendritic cells. Originate from myeloid progenitors. In the mature form, these cells capture antigens and bring them to lymphoid organs to stimulate T-cell response.

T cells. These cells mature in thymus. They have multiple forms and sub-forms differentiated by function, types of cytokines released and indicated by cell surface markers. These include cytotoxic $(C D 8+)$, helper $\left(C D 4+\right.$ or $\left.T_{h}\right)$, or regulatory $\left(\mathrm{T}_{\text {reg }}\right)$.

B cells. Cells mature in bone marrow. They have many forms depending on stage of maturation. Plasma B cells produce antibodies. starting to examine which cytokines may be related to depression, anxiety disorders and the antidepressant response.

\section{SEX DIFFERENCES IN THE IMMUNE SYSTEM}

Females have larger populations of most innate and adaptive immune cells (Fig. 1) along with higher the basal level of immunoglobulins [63]. Women respond more robustly to infections, with increased cytokine production and T-cell response [64], and also have a lower incidence of parasitic infection [65]. Women are more resistant to bacterial infections, and respond more robustly to vaccines than men $[65,66]$. It is possible that these stronger immune responses to pathogens may contribute to the higher incidences of autoimmune disease, allergies and asthma that are also observed in women. These distinct, and sometimes divergent, sex-specific responses to immune system challenges are of particular importance when considering both therapeutic interventions and pathological consequences of inflammation.

\section{GENETICS \& EPIGENETICS}

Sex chromosomes are intricately involved in the development and organization of the immune system (Fig. 1). The $X$ chromosome contains more immune-related genes than any other chromosome [67]. Some genes residing on the $X$ chromosome are resistant to inactivation, resulting in a double dose of the gene product for females [68]. These include genes involved in T-cell function such as CD4OLG that regulates communication with $\mathrm{B}$ cells, and the chemokine receptor CXCR3. The double dose of these genes in women, resulting from escaping X-inactivation, may contribute to increased autoimmune disease, as well as improved immune responses to infection [69]. X-linked primary immunodeficiencies, which affect males who have no backup for mutations in genes on their single $X$ chromosome (Fig. 1) can be catastrophic and include severe immunodeficiency [70]. Other mechanisms of sex differences in immune composition and function include the microRNAs located on the $X$ chromosome [71], such as mir-98, which regulates the bacterial response of epithelial cells resulting in sex differences in levels of proinflammatory cytokines.

The $Y$ chromosome contains genes that epigenetically regulate immune system gene transcription. $Y$ chromosome regulation of alternative splicing in immune system-related genes, as well as changes in chromatin dynamics, alter expression of genes implicated in autoimmune disease [72]. The four-core genotype mouse model, in which the Sry gene is manipulated, has allowed researchers to further dissect out the role of genetic sex from gonadal sex [73]. Sry is found only on the $Y$ chromosome and is necessary for differentiation and maturation of the testes. In the four-core genotype model, Sry is removed from the $Y$ chromosome in males, resulting in an $\mathrm{XY}^{-}$genotype that develops female gonads. To make genetic females or $\mathrm{XY}^{-}$males express male gonads, the Sry gene is inserted onto an autosome [73]. When four-core genotype mice were injected with myelin basic protein, the $Y$ chromosome stimulated immune function in the absence of testosterone. In intact mice, testosterone was immunosuppressant and occluded effects of the Y chromosome [74]. The XX genotype, regardless of gonadal phenotype, was associated with increased immune response [74], along with increased rate of development of experimental autoimmune encephalomyelitis and pristaneinduced lupus compared with XY mice in other studies [75], suggesting an important role for genetic sex in determining immune function and response.

\section{HORMONES}

Gonadal hormones including estrogens, progestins, and androgens all influence immune cell populations, activation by 


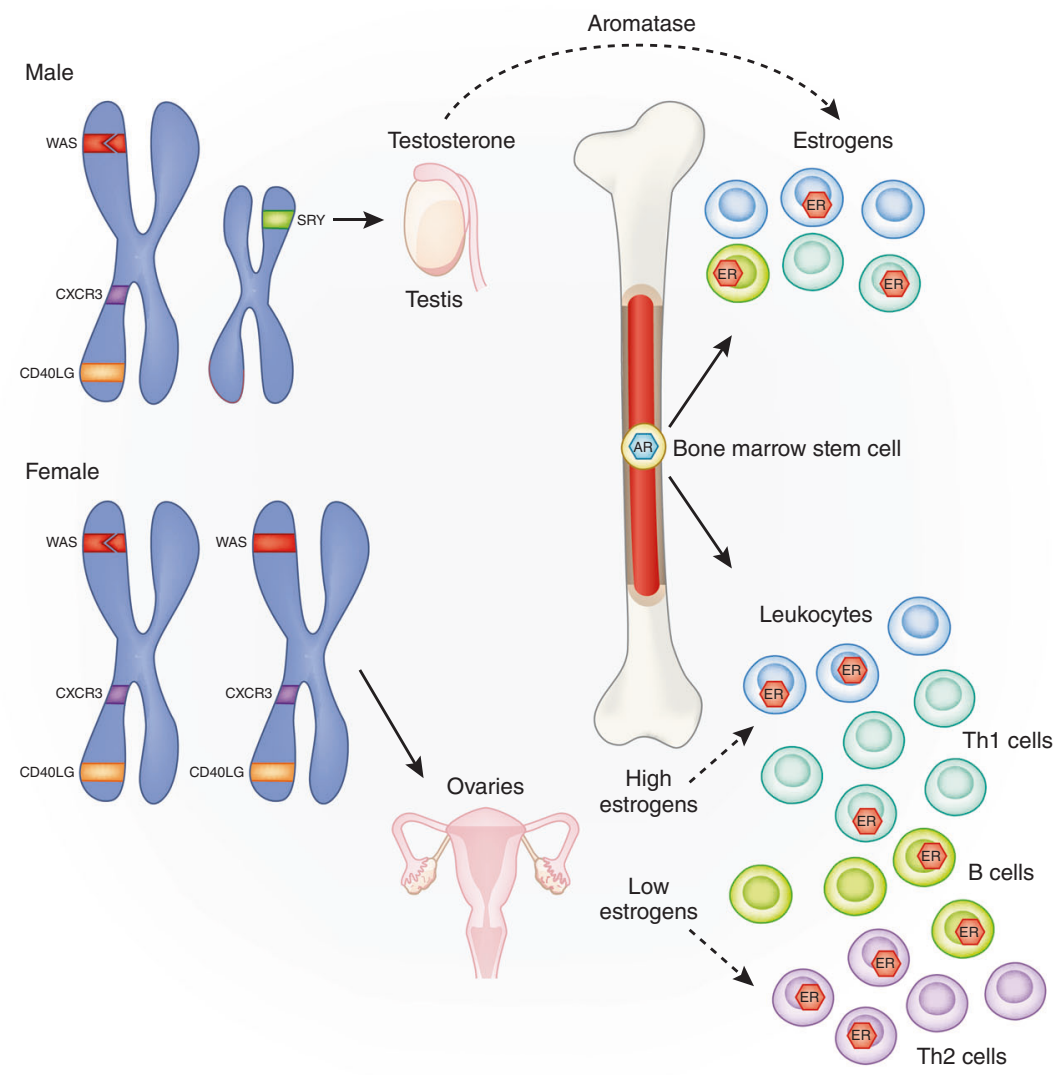

Fig. 1 Genetic and hormonal sex contributes to differences in the immune system. Multiple immune genes such as CXCR3 and CD4OLG on the $X$ chromosome escape inactivation resulting in dosage effects. Other genes such as the Wiskott-Aldrich syndrome (WAS) can undergo mutations resulting in male-specific compromise of the immune system. In males, the gene Sry on the $Y$ chromosome is a transcription factor that begins the process of testis differentiation. Testosterone, synthesized and diffused from the testis, acts on androgen receptors to induce apoptosis of stem cells in the bone marrow niche, resulting in reduced immune cells. Testosterone is also aromatized into estrogens to act on estrogen receptors in immune cells. Low levels of estrogens act on T cells to produce a skew toward an anti-inflammatory Th2 profile, whereas high levels of estrogens skew the population towards a Th1 pro-inflammatory profile

pathogens, antibody production, and even immune organ development [76-81]. Gonadal hormones act to organize aspects of the immune system during development [82]. For example, estrogen receptor alpha (ER-a) is necessary for the proper development of thymus and spleen in male mice [80]. Activational effects of estrogens are dose dependent [83] at low doses they can stimulate the immune system [84], whereas, at high doses estrogens are immunosuppressant [85, 86], which has interesting implications for variation in immune response across the estrous/menstrual cycle, puberty, parturition, and menopause [87]. Estrogens can increase secretion of interleukins (IL) by dendritic cells, increase specific antibody secretion by B cells and increase populations of regulatory $T$ cells $\left(T_{\text {regs }}\right)$, a type of suppressor $T$ cell, that decrease proliferation of effector $T$ cells and helps maintains tolerance to self [88]. Androgens are generally immunosuppressive. Males have fewer effector $\mathrm{T}$ helper $\left(T_{h}\right)$ cells than females owing to apoptotic signaling via testosterone in the bone marrow (Fig. 1) [77, 79]. As a result, males experience less protection from vaccines and greater susceptibility to infections $[78,89]$.

Sex differences in the hypothalamic-pituitary-adrenal (HPA) axis mediate immune function differently in males and females and likely contribute to sex differences in mood disorders. Acutely stressful conditions increase the production of corticotropin-releasing factor (CRF) in the hypothalamus, which causes release of adrenocorticotropic hormone (ACTH) from the anterior pituitary. ACTH acts on the adrenal cortex to stimulate the production and release of hormones termed glucocorticoids; primarily cortisol in humans or corticosterone in rodents. Glucocorticoids are released into the body to mobilize glucose to fuel muscles. Glucocorticoids act to bring the spike in pro-inflammatory cytokine expression back to baseline [59], and provide negative feedback to stop the production of CRF and ACTH in the brain. Therefore, immune system activation in response to stress or attack may occur prior to the release of the glucocorticoids and potentially triggers CRF activation.

Acute and chronic stresses have opposite effects on directing the immune response in animal models. There is a redistribution of leukocytes from blood to organs following acute stress, [90, 91] dependent upon GRs, that leads to an increased immune response within the tissue [92]. Chronic stress reduces the redistribution of cells into tissue, disrupts circadian corticosterone rhythm, and attenuates its response to stress [93]. Glucocoticoids bind to both the glucocorticoid (GR) and mineralocorticoid receptor (MR). GR and MR are nuclear receptors that act as transcription factors in both liganded and unliganded states; therefore, specific concentrations of glucocorticoids and the ratio of receptors present can result in very different responses depending on cell type [75, 94]. GRs and MRs are expressed throughout the body and brain, including on lymphocytes and macrophages [95]. HPA axis activation following social stress in male mice results in increased adrenal corticosterone production, increased release of monocytes from the bone marrow into 


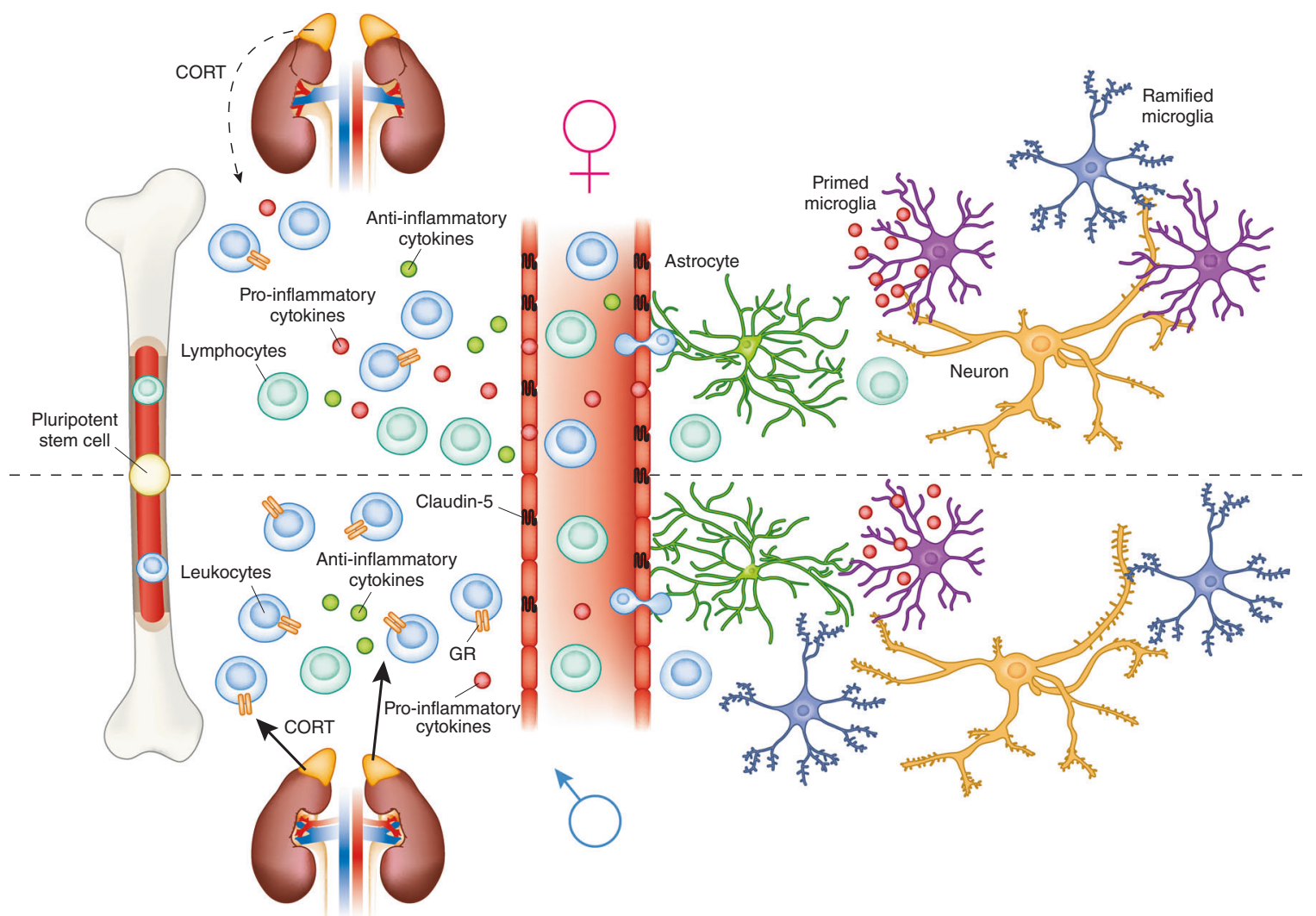

Fig. 2 Potential immune mechanisms of sex differences in mood disorders identified from pre-clinical studies of stress. There are sex differences in the populations of lymphocytes and leukocytes released from bone marrow. Females have more circulating leukocytes and lymphocytes than males. Females exhibit little or no glucocorticoid feedback on immune cell activation following stress, which may lead to a dysregulated ratio of pro-inflammatory to anti- inflammatory cytokines in the periphery. In the nucleus accumbens, Claudin-5 a tight junction protein is downregulated in patients with depression and male mice allowing increased permability of the blood brain barrier for cytokines and possibly monocytes and T cells. Within the brain, adult female rodents are reported to have more primed microglia than males, which may alter their activation by stress. In males only, stress increases spine density on medium spiny neurons in the nucleus accumbens

circulation (Fig. 2), and potentially increased recruitment of monocytes to the brain [96, 97]. Adrenalectomy or pharmacological inhibition of corticosterone synthesis attenuates mobilization of monocytes from the bone marrow, suggesting that corticosterone signaling is necessary for the release of monocytes into circulation [98].

Overall hyperactivity of the HPA axis, with decreased GR sensitivity, is common in patients with major depression and bipolar disorder [99, 100]. At baseline, cortisol levels are not different between healthy controls or patients of either sex with MDD, rather MDD increases plasma cortisol concentrations during the period immediately following cessation of a stressor, suggesting impaired stress recovery and resulting in extended exposure to increased cortisol levels [101]. Perimenopausal women in remission to MDD responded to mild stress with hyperactivation of the HPA axis [102], although some responded to psychosocial stress with hypoactivation of the HPA axis [103]. These seemingly contradictory findings may be explained by patient age and the type of stress used. Hypoactivation was observed following psychosocial stress in slightly older women, $49 \%$ of whom were postmenopausal [103], whereas hyperactivation was observed in perimenopausal women following mild visual stress [102]. Therefore, differences may exist across menopause, which along with stressor type may have different effects on the HPA axis response. In patients with PTSD, there are reports of both hyperactivity and hypoactivity of the HPA axis in response to stress [104], which has implications for immune regulation. Under non-pathological circumstances, stress resulted in increased cortisol that decreased the production of pro-inflammatory cytokines and increased anti-inflammatory cytokines produced from peripheral blood mononuclear cells [105]. In pathological circumstances, excessive activation of proinflammatory cytokines reduced the sensitivity of GR; for example, IL-1a inhibited GR nuclear translocation, which caused a decrease in GR-mediated transcriptional effects [106].

The interaction of the immune response to stress and glucocorticoids is different in men and women. Male glucocorticoid sensitivity was increased $1 \mathrm{~h}$ following psychological stress, whereas the opposite effect was observed in females (for review see ref. 107) Anticipation of a stressor increased ACTH and free cortisol as much as two times in men compared with women [108]. When lipopolysaccharide (LPS) was injected into people following stress, there was a reduced stimulation of cytokines in men and an increased response in women, suggesting decreased glucocorticoid feedback on the immune system in women [109].

Studies in rodents support the concept that HPA axis activity is sexually differentiated. GR knockout in the forebrain increased depression-associated behavior in male but not female mice [110]. GR knockout in the paraventricular nucleus of the hypothalamus in male mice resulted in increased levels of stress hormones following acute stress, whereas the opposite occurred in females [111]. There are sex differences for CRF receptor 1 signaling and trafficking that make females more sensitive to CRF than males and alter their norepinephrine (NE) response, making them less able to downregulate NE production in response to arousal [112]. The autonomic nervous system, in turn, is a key regulator of the immune system. Release of NE through the sympathetic nervous system activates $\beta$-adrenergic receptors in perivascular niche cells 
that lead to diurnal release of hematopoietic stem cells [113]. Sex differences in autonomic regulation of blood pressure are known in the human medical literature and vary across reproductive status in women [114]. Higher sympathetic activity oppositely regulates augmented pressure in young men and women [115] and $\alpha$ - and $\beta$-adrenergic receptors have different effects on vasoconstriction [116-118]. If sex differences exist in the autonomic regulation of blood pressure and the HPA axis, it is probable that these sex differences also mediate immune effects [119].

\section{INTERACTIONS BETWEEN BODY AND BRAIN}

Traditionally, the central nervous system (CNS) was characterized as an immune privileged area, particularly under non-pathological circumstances [120]. We now know there is more immune trafficking between the periphery and the brain than previously thought [121-124]. The CNS is an immunologically active organ for which stress differentially activates various innate immune cells and alters protection from a multitude of pathogens by the blood-brain barrier (BBB). Many cytokines are selectively allowed to cross the $B B B$, including IL-1a, IL-1 1 , IL-1ra, IL-6, tumor necrosis factor alpha (TNF-a), leukemia inhibitory factor, and ciliary neurotrophic factor [125], many of which have implications for neuropathologies, including mood disorders [126].

$A$ recent study using postmortem tissue from patients and an animal model demonstrated a relationship between BBB integrity and stress susceptibility [127]. Decreased expression of the endothelial tight junction protein claudin-5 (Cldn5) was found in the nucleus accumbens (NAc) of patients with MDD. Antidepressant treatment at the time of death partially rescued Cldn5 expression. The functional relevance of Cldn5 expression was examined using social defeat stress, a resident/intruder paradigm, which models depression and PTSD in mice [128]. After 10 days of social stress, there was a natural division in which $\sim 70 \%$ of mice engaged in behaviors associated with depression, including social avoidance of a novel animal and anhedonia, whereas $\sim 30 \%$ of mice that had the same stressful experience were resilient and behaved similarly to controls [129]. Stress-susceptible mice had downregulation of Cldn5, and conditional knockdown of Cldn5 in the NAc, combined with subthreshold defeat, was sufficient to induce depression-like behaviors [127]. The effect of reducing Cldn5 expression was to increase BBB permeability, allowing cytokines to infiltrate the NAC (Fig. 2), including a labeled IL-6 demonstrating that peripheral cytokines were detectable in brain after stress. Furthermore, IL-6 injection directly into the NAC induced social avoidance behavior following micro defeat demonstrating that increased IL-6 in NAC was sufficient to produce a stress susceptible phenotype [127]. A new study using a rodent model of learned helplessness further supports the role of Cldn5 in stress induced BBB permeability. They found that permeability was mediated by TNF-a, along with a potential role for other tight junction proteins such as occludin and zona occludens-1 [130].

Previous studies indicate that stress allow for infiltration of monocytes from the periphery into the parenchyma of some brain regions in males [124, 131]. Repeated social disruption stress involves repeatedly changing the social dynamic of a group of male mice by adding in a larger, aggressive intruder into the home cage [132]. After stress, male mice display anxiogenic behavior [124], altered monocyte transcriptome, including upregulation of proliferation- and inflammatory-associated genes, and upregulated myelopoiesis, resulting in potentially harmful inflammatory states [133]. Neutrophils and monocytes accumulate in blood circulation and spleen [132] and may also traffic to the brain and release cytokines [134, 135], or potentially the meninges [127], allowing them to release cytokines that can pass through or further act on the BBB (Fig. 2). These data provide strong evidence for mechanisms by which inflammatory cytokines released peripherally in response to stress may influence depression-like behaviors through direct interactions with cells of the CNS.

Additional evidence of the relationship between mood disorders and altered endothelial/epithelial cell integrity come from studies of gut microbiota. Although most evidence of BBB permeability is ongoing and unpublished, the tissues that line the gut and brain are similar and there seems to be a synchronicity of effects of stress on gut and brain through the same mechanisms $[136,137]$. Studies on germ-free mice or examining antibiotic treatment in the early prenatal period have implicated gut bacteria, acting on gut permeability, as playing an important role in the development of anxiety-associated behavior and the endocrine stress response [138]. Recolonizing the gut can change anxiety-related behavior, particularly at early postnatal time points [139]. Microbiota influence microglia development, along with response to activation in adulthood [140]. Early evidence of a relationship between gut microbiota and depression came from a study of human subjects with depression. Depressed patients had higher concentrations of antibodies against LPS, suggesting increased gut permeability, which was thought to increase basal concentrations of pro-inflammatory cytokines [141].

Fecal microbiota transplants from patients with depression into germ-free rats increased anhedonia and anxiety-associated behavior along with changing metabolism of tryptophan [142]. Depressed patients have decreased diversity of gut microbiota and increased circulating levels of inflammatory cytokines [142]. Altered microbiota distribution was also found in patients with polycystic ovarian syndrome [143], a disease that in a subset of women is associated with increased circulating levels of androgens, decreased fertility, obesity, increased insulin insensitivity, and high rates of depression [144]. In patients with bipolar disorder, there is a reduction in the variability of gut microbe populations compared with healthy controls. The over-abundance of specific types of gut bacteria correlate with the patient's physical health, depression symptoms, and sleep patterns [145]. Additional studies have implicated compromised gut and increased serum antibody levels for fungal pathogens, such as yeast, in female patients with bipolar depression and male patients with schizophrenia [145, 146].

Studies on animals indicate there are sex differences in gut microbiota [147-149]. Sex differences emerge at puberty, when males start to diverge from females, and differences continue as animals age [150]. These differences have implications for the treatment of mood disorders; male mice given a fatty acid diet supplementation had changed microbiome profiles and reduced anxiety and depression-like behaviors following isolation stress, whereas the same treatment had no effect in females [149]. Sex will be an important factor in studies attempting to treat mood disorders by changing the composition of the microbiome.

\section{SEX DIFFERENCES IN THE PERIPHERAL IMMUNE SYSTEM ACROSS HORMONAL MILESTONES}

The relationship between the immune system and depression was identified through studies that found administration of interferona was sufficient to induce depression in patients being treated for hepatitis, even in the absence of a history of mood disorders [151]. Cytokines elevated in patients diagnosed with depression include IL-8/IL-1 $\beta$ in the elderly [152], along with TNF- $\alpha$ and IL-6 across multiple studies, ages and sexes [153-155]. IL-6 can stimulate T and $B$ cells, which can contribute to chronic states of inflammation [156], that may be implicated in depression.

The increased incidence of depression in women begins at puberty [157], and continues during the reproductive years, when estradiol levels are at their highest and undergo cyclic variation [158]. Puberty, via the action of estrogens and androgens, induces 
activational sex differences in the immune system [159]. Early maturation in girls, defined as the onset of menarche prior to 11.5 years of age, is associated with both increased circulating levels of estrogen, and an increased risk of depressive symptoms during adolescence [160]. Although gonadal hormones act on the immune system during puberty, the immune system itself is also involved in pubertal development. During adolescence, the immune system is involved in breast maturation [161], changes in the vaginal tract [162] and testis development/sperm production [163, 164]. A longitudinal study in boys and girls from ages 8 to 15 suggests that increased circulating cytokines related to obesity during puberty potentially contribute to female depression. Obesity, a factor in inflammation, depression, and early onset of puberty, resulted in elevated levels of IL-6, IL-8, and IL-10 in girls but not boys across pubertal development [165]. In healthy normal weight children, IL- 6 decreased across puberty in both boys and girls and negatively correlated with both testosterone and estradiol levels [166]. As circulating levels of IL-6 at age 9 predicted a greater likelihood of developing depression or psychosis by age 18 in both genders [153], the obesity related increases in IL-6 may be a contributing risk factor for pubescent onset of depression in girls.

Postpartum depression also ties immune response to hormonal changes. Approximately $10-20 \%$ of new mothers experience postpartum depression [167]. Different stages of pregnancy are normally associated with changes in inflammatory state. Pregnancy begins with an increase in pro-inflammatory cytokines that shift to an anti-inflammatory state during the majority of gestation, allowing for tolerance of the growing fetus. Right before delivery there is a surge in pro-inflammatory cytokines [168]. One theory holds that women who experience postpartum depression have a shift toward greater pro-inflammatory $T_{h} 1 / T_{h} 17$ activation during the pregnancy [169]. In women who later developed postpartum depression, IL-10, an anti-inflammatory cytokine, was found to be significantly decreased in late pregnancy [168], providing further evidence that a stronger shift to a pro-inflammatory state may influence susceptibility to postpartum depression.

C-reactive protein (CRP), a marker of low-grade inflammation, was increased in a subset of patients with immune-related depression [154], and levels of CRP were also increased during pregnancy in patients at risk for postpartum depression [170]. However, a longitudinal study reports that CRP during the third trimester was not related to subsequent postpartum depression scores [171]. They reported lower levels of circulating IL-6 and IL10 during the third trimester moderately predicted postpartum depression scores. These data suggest a suppression of both pro and anti-inflammatory cytokines during the third trimester was a risk factor for postpartum depression rather than overactivation of pro-inflammatory cytokines.

Women with a previous diagnosis of bipolar disorder are more vulnerable to psychiatric complications associated with pregnancy, than the general population. Mothers with a previous diagnosis of bipolar disorder had a relative risk, calculated as the probability ratio of an event occurring in one group versus a control group, of 37.22 of readmission for psychiatric illness within 10-19 days postpartum [172]. There was also an increased risk of first episode of bipolar mania or psychosis following childbirth. Around $14 \%$ of women, admitted for the first time with a psychiatric episode following childbirth, developed bipolar disorder [173]. In general, there is a higher incidence of firsttime postpartum psychiatric issues in women who experience autoimmune attacks during or after pregnancy, including preeclampsia [174] and thyroid dysfunction [175]. When defining postpartum psychosis as any postpartum psychiatric diagnosis that includes psychotic features (depressive, manic, or mixed), researchers found an inflammatory shifted profile of cytokines and immune cells in blood even in the absence of autoimmune disease [176, 177]. Pro-inflammatory alterations included increased monocytes, failure to reduce NK, and B cells, along with a reduction in $T$ cells, particularly $T_{h} 1$ cells, which are normally increased in healthy postpartum controls [177]. Additional studies have replicated the overall decrease in $T$ cells in mothers with postpartum psychosis and discovered that within Tcell populations, activated CD8 + and $T_{\text {regs }}$ were increased [176].

Recent work in animal models of normal pregnancy and postpartum depression are starting to uncover potential immune mechanisms contributing to the increased vulnerability to mood disorders during this period of hormonal changes. Studies on subthreshold stress during the last week of pregnancy uncovered pregnancy specific changes of cytokine profiles in the brain and decreased numbers of microglia that may contribute to symptoms associated with mood disorders [178]. Both stressed and non-stressed postpartum females expressed increased anhedonia. Subsequent examination of immune changes in the brains of rats across late pregnancy and postpartum report decreased microglia number in brain areas associated with human mood disorders [179]. In particular, the authors found that only ramified microglia were downregulated but all animals recovered to rates expressed in virgin females by 21 days postpartum [179]. Protein levels of IL- 6 and IL10 were elevated in the hippocampus of these females on postpartum day 8 in the absence of other cytokine changes supporting the previously reported dysregulation of the relationship between pro- and anti-inflammatory cytokines in this region and the pre-frontal cortex $[178,179]$. As increased cytokine protein levels were found when microglia were decreased, they potentially have a different source. Previous studies of rodent postpartum depression models report increased peripheral cytokines produced by stimulated whole blood including IL-1 $\beta$, TNF-a, and IL-10 [180].

Many women experience their first episode of a mental illness, or worsening symptoms, during perimenopause [181]. About $20 \%$ of women experience extreme symptoms of menopause [182], and there is an increased risk of newly diagnosed psychiatric disorders in these women compared with those with low or asymptomatic menopause. Menopause is also accompanied by increased circulating levels of pro-inflammatory cytokines [183]. Long-term exposure to mental illness may result in different profiles during aging. A study on bipolar disorder in both genders during middle age found decreased T cells along with changes in sub-populations of effector and regulatory $T$ cells suggesting dysregulation of inflammation in the adaptive immune system [184]. The same patients did seem to have normal glucocorticoid regulation of monocytes, indicated by increased GR-a and decreased transcription for pro-inflammatory genes. The role of gonadal hormones in depression and anxiety is not limited to women [185]. Men with reduced testosterone levels owing to hypogonadism also have a higher incidence of depression compared with men with normal testosterone levels, and testosterone replacement therapy has been shown to reduce depressive symptoms [186]. Andropause, a constellation of symptoms including changes in libido, mood, weight and energy is associated with the naturally occurring decline in androgens during middle age [187]. Andropause symptoms evaluated with the Aging Males Symptom scale positively correlated with severity of depression in men [188, 189]. Anxiety and depression were associated with aging in human males but only depression was also associated with some, but not all, sexual dysfunction [187]. As androgens suppress the inflammatory response [89], the greater activation of the immune system in males with reduced testosterone levels may also be a potential mechanism of mood disorders. It will be difficult to tease apart the normal influence of aging on the immune system from the endocrine based effects in humans [4], therefore, this would be an important area to study using animal models. 


\section{SEX DIFFERENCES IN CENTRAL IMMUNE MECHANISMS}

The immune cells within the brain that have been studied the most are microglia. Microglia are brain macrophages, and are highly mobile in their quiescent/ramified state when they scan the brain for pathogens [190]. Microglia transition through a primed/ activated state into a reactive/ameboid state to kill and phagocytize anything that is recognized as dangerous or nonself $[190,191]$. Microglia have the ability to release pro- or antiinflammatory cytokines along with reactive oxygen species when activated [190, 192-194].

The data from human postmortem studies on the relationship between microglia activation and mood disorders is limited, in part, because there is a stronger relationship between microglia activation and suicide, regardless of the type of psychiatric disorder. Studies that examined tissue from patients with schizophrenia, affective disorders, or no history of a psychiatric disorder who committed suicide, reported increased microglia activation [195-197]. The majority of successful suicides were committed by men [198], so any study that did not control for sex of subject and/or type of death will skew male, which may further cloud the relationship between depression and microglia activation if sex differences exist. A recent study examined large-scale differences in gene expression across multiple mental illnesses and demonstrated that transcriptional modules associated with astrocytes and microglia differentiation were upregulated in cortical tissue from patients with bipolar disorder, autism, and schizophrenia, but were not significantly regulated in patients with MDD [199]. However, the same study did show MDD-specific upregulation of genes associated with cytokine-cytokine interactions and hormone activity, suggesting there are different patterns of regulation but perhaps not microglia activation.

In vivo imaging studies have used PET imagining of translocator protein (TSPO) density in participants undergoing a major depressive episode or following LPS administration [200-202]. TSPO is a labeled ligand that is expressed when microglia are activated from their resting state. TSPO is also present in astrocytes and endothelial cells [203], so specificity of the described effects are limited. Subjects experiencing MDD or administration of LPS had increased TSPO density across all measured brain regions $[200,201]$. TSPO density in the anterior cingulate cortex significantly positively correlated with subject's score on the Hamilton depression rating scale. However, there is conflicting data as a different study found a non-significant decrease in TSPO density in all of the brain regions studied [202]. No studies have found a positive correlation between peripheral cytokine levels and TSPO density; if anything, peripheral cytokine levels and CRP were either not significantly correlated at all or negatively correlated with TSPO density [201]. These data suggest that a simple model where peripheral cytokines directly activate all types of immune cells in the brain is unlikely. Because TSPO is not specific only to microglia it is possible that there are opposite effects of peripheral cytokines on astrocytes and microglia that may cancel each other out. There is some evidence from postmortem amygdala tissue that depression is involved in a downregulation of the astrocyte marker glial fibrillary acidic protein [204], and this downregulation is also found in multiple limbic brain regions in a rodent depression model [205]. It is also possible that peripheral immune activation is acting directly on neurons rather than through microglia. To date, none of the human imagining studies have examined sex as a factor, which also may contribute to our limited understanding of the role of microglia activation in depression.

Studies on animals indicate there are sex differences in microglia, particularly during development [193, 206, 207], which is reviewed elsewhere in this issue. The microbiome influences microglia development sex-specifically in utero [208]. In the embryonic period, male offspring of germ-free mothers had altered microglia transcriptome profiles with over 1000 genes differing from male offspring of mothers with standard microbiota, whereas only 20 genes were differentially regulated in females. Effects were reversed in adulthood, females born to germ-free mothers had $\sim 400$ genes differently expressed in their microglia, whereas only 26 genes differed in males. Female microglia also had faster maturation and higher expression of genes associated with inflammation, apoptosis, and response to LPS $[207,208]$. Immunohistochemistry data from adult female rodents suggest that microglia are more frequently in a primed state under baseline conditions than males [209]. This is in opposition to what is found in the prenatal rodent brain in which males have more primed microglia [210]. Exposure to acute or chronic stress increased the proportion of ramified: primed microglia in females, but not males, meaning female activational state shifted to an anti-inflammatory profile after stress exposure. Even when microglia in females were activated to the same degree as males, their effects on mood related behavior were not the same [211]. Male and female rats exposed to microembolic stroke had different anxiety-related responses following recovery. In males, there was some evidence that microglia activation drives stress induced anxiety through a recruitment of IL-1 $\beta$-expressing monocytes [96]. Recent studies have also shown a role for increased phagocytic activity and increased proliferation of microglia in male mice exposed to social defeat stress [212]. Future research will be needed to determine if these effects on microglia are sex specific.

\section{IMMUNE RESPONSE TO SOCIAL STRESS IN ANIMAL MODELS}

In animal models of mood disorders that utilize social stress, there is growing evidence that immune mechanisms contribute to vulnerability. Social defeat stress in mice induces social avoidance and anhedonia in stress-susceptible mice, although some mice remain resilient. Susceptible and resilient mice differed in the amount of IL- 6 measured from blood within 20 min of the first exposure to an aggressor and these differences lasted up to 30 days after the last stress exposure [213]. Individual differences in the immune system predated exposure to stress and predicted subsequent behavior. Animals that were susceptible to social defeat stress had a pre-defeat profile that included more circulating white blood cells that, in turn, were more sensitive to immune stimulation and released more IL- 6 into circulation [213].

A new method of inducing male mice to attack female mice through designer receptors exclusively activated by designer drugs activation of ER-a in the ventral lateral subdivision of the ventral medial hypothalamus has allowed for examination of circulating IL- 6 in female mice exposed to social defeat stress [214]. After 10 days of social defeat stress susceptible group housed females had higher circulating levels of IL-6 than resilient or control mice. Single housing female mice after social defeat elevated levels of IL-6, regardless of whether they were behaviorally susceptible or resilient to the stress [214]. Males are usually single housed after social defeat stress [128], therefore these data suggest that the isolation in females may be a greater additive stressor than in males, as it occludes any differences in IL6 caused by the defeat itself.

A variation on social defeat stress is vicarious social defeat, which can also be performed in females [215-217]. Here, the experimental animal watches a conspecific undergo social defeat stress. The experimental animal has no physical contact with the aggressor, he/she only witnesses the aggressor interact with another animal. Therefore, any change in cytokines is due solely to the emotional experience of watching the defeat and not caused by wounding. Male mice had significantly elevated levels of IL-6 after witnessing social defeat [213]. A number of inflammatory cardiac factors were altered following social defeat stress [218, 219], and were replicated in vicarious social defeat stress [220]. As this model is now being used in females [215], it will be very 
interesting to examine cytokine profiles and determine whether the same peripheral indicators of stress are activated in both sexes.

There is some causal evidence implicating opposite effects of the adaptive and innate peripheral immune system directly in stress vulnerability in male mice. Studies of the adaptive immune system suggest a protective role for the effects of stress on immune function. Rag $2^{-/-}$mice, which lack mature lymphocytes, produced anxiolytic/antidepressant-associated behaviors when given mature lymphocytes from animals exposed to social defeat stress but not home cage controls [221, 222]. Even though the animals originally exposed to stress had elevated circulating levels of pro-inflammatory cytokines, adoptive transfer of their lymphocytes resulted in subsequent reduction in those same proinflammatory cytokines and an increase in the anti-inflammatory cytokine IL-4 [222]. Studies of the innate immune system found a relationship between pro-inflammatory cytokines and the development of stress susceptibility or resilience. Bone marrow transplant from an IL-6 knockout (KO) mouse into a wild-type host mouse prevented development of social avoidance following either social defeat stress or vicarious social defeat stress [213]. IL6 peripheral $\mathrm{KO}$ acted in part by blocking the ability of stress to increase plasticity in the nucleus accumbens, indicated by changes in post-synaptic density protein 95 that were normalized to control levels in mice given bone marrow transplants from IL-6 KO mice [223]. Bone marrow transplants from mice that were already susceptible to social defeat stress shifted experimental animals into expressing social avoidance behavior following subthreshold defeat and increased their circulating levels of IL-6 $[213,223]$. These functional peripheral immune responses are thought to act through the innate immune system, in particular through the action of monocytes $[213,223]$. Peripheral cytokines can influence stress susceptibility or can ameliorate its effects directly through peripheral actions. Many studies have used peripheral cytokines as proxies for changes occurring in the brain. Data from a rat version of social defeat stress indicates that peripheral cytokine expression does not match cytokine changes occurring in the brain [224]. Together these data indicate that peripheral cytokines have the potential to be useful biomarkers of disease state in their own right and are potential targets for treatment.

\section{BIOMARKERS}

One of the major issues with finding appropriate inflammatory biomarkers for mood disorders is that the same cytokines are elevated across different disorders. For example, circulating IL-6 is elevated in depression, schizophrenia, bipolar disorder, anxiety disorders, and autism spectrum disorders [225-228]. A few studies have examined sex as a factor rather than controlling for it as a covariate when exploring biomarkers and are noted in Table 1. Sex is an important variable in understanding acute and long-term relationships between the immune system and mood disorders. For example, a longitudinal study that examined circulating levels of cytokines in mothers during pregnancy found different relationships between immune activity during the pregnancy and the risk of the offspring developing depression when the baby reached adulthood. High maternal TNF-a:IL-10 during pregnancy reduced the risk of depression in men but increased it in women [229].

Non-cytokine focused studies also suggest that biomarkers may be sex specific. Antibodies for the gram-negative gut bacteria Helicobacter pylori, implicated in the presentation of gastritis and ulcers, were associated with an increased risk of dysthymia in premenopausal women but a decreased risk in men, a similar relationship was found for depression and the herpes simplex virus, cytomegalovirus [230]. Studies of white blood cell deviations from the median were associated with reductions in appetite, reductions in sleep, severity of sadness, concentration issues, apathy, and suicidal ideation [231]. This relationship was more pronounced in men than in women, with correlations of white blood cell deviations to Montgomery-Asberg depression rating scale (MADRS) score only reaching significance in the male subjects. Urinalysis studies using multiple methods have revealed sex-specific metabolite biomarkers for MDD, with higher diagnostic accuracy than non-sex-specific screens [232]. Together these studies highlight the need for sex-specific research in developing diagnostic biomarkers for depression.

\section{SEX DIFFERENCES IN TREATMENT RESPONSE}

Selective serotonin reuptake inhibitors (SSRIs) are the first line of treatment for both unipolar depression and anxiety disorders, even though they are anxiogenic at the onset of treatment (for review, see ref. 233). Remission occurs in $\sim 40 \%$ of the population following initial treatment and in those given successive treatments the cumulative rate of remission is $~ 67 \%$ [234]. Women of reproductive age with depression have a higher rate of remission when treated with SSRIs, such as sertraline, whereas, men and postmenopausal women respond better to tricyclic antidepressants, including imipramine $[13,235,236]$. There is also evidence that monoamine oxidase inhibitors are the most effective treatment for atypical depression, which is more common in women than men [237]. Bipolar disorder has been traditionally treated with lithium and/or valproates as mood stabilizers [238, 239]. Response to lithium, valproate semisodium or both drugs given in combination did not differ by sex $[240,241]$. Rates of response to lithium were $\sim 60-65 \%$ and rates of response to valproate were around $69 \%$. Lithium in combination with valproate or lithium monotherapy was more likely to prevent relapse than valproate alone over a 2-year period [241]. That said, women given lithium were around three times more likely than men to develop hypothyroidism [242]. Together these data indicate that $\sim 30 \%$ of the population with mood disorders are not responding to current treatments. There is a developing interest in altering the immune system to treat people with mood disorders, particularly those that are currently treatment resistant.

\section{CYCLOOXYGENASE (COX) INHIBITORS AND NON-STEROIDAL ANTI-INFLAMMATORIES (NSAIDS)}

Increased levels of prostaglandin E2 $\left(\mathrm{PGE}_{2}\right)$ have been reported in depressed patients, as well as in animal models of inflammationinduced depression-like behaviors. NSAIDS decrease prostaglandin synthesis by COX inhibition, and studies in male mice demonstrated a reduction in depression-like behaviors in response to ibuprofen treatment that was similar in effect to treatment with fluoxetine, potentially through elevation of PGE2 and nitric oxide levels in the brain [243]. However, it has also been reported that concurrent treatment with SSRIs and NSAIDs in both mouse models and in patients with diagnosed depression resulted in reduction of the antidepressant effects of SSRI treatment alone [244]. A study using men and women reported that the type of NSAID impacts the interactions with SSRIs, and concluded that ibuprofen or low-dose aspirin treatment may actually be beneficial in the treatment of depression; SSRIs with acetaminophen also decreased the risk of psychiatric contacts, but increased risk for cardiovascular mortality [245]. Unfortunately, sex was not included as a variable. Recommendations for dosage are the same for all adults, regardless of body weight, despite the evidence for differences in metabolism of these drugs in men and women [246]. For example, acetaminophen clearance was $22 \%$ higher in men than in women; interestingly, women using oral contraceptives use had a $49 \%$ higher clearance than control women, which made their clearance rates even higher than males [247]. 
Table 1. Peripheral biomarkers of mood disorders

\begin{tabular}{|c|c|c|c|}
\hline Disorder & Biomarker & Direction of effect & Sex difference \\
\hline \multirow{14}{*}{ MDD } & GM-CSF & Up & Did not differentiate by sex [226] \\
\hline & $\mathrm{IFN}-\gamma$ & Up & Women only [266] \\
\hline & $\mathrm{IL}-1 \beta$ & $\begin{array}{l}\text { Up or }+ \text { Correlation with } \\
\text { symptoms }\end{array}$ & Did not differentiate sex [265] In women only [266] \\
\hline & IL-5 & Down & In women only [266] \\
\hline & IL-6 & $\begin{array}{l}\text { Up or }+ \text { correlation with } \\
\text { symptoms }\end{array}$ & $\begin{array}{l}\text { Did not differentiate sex }[226,265,268,269] \text { In women [267] Higher in depressed } \\
\text { women than men }[266]\end{array}$ \\
\hline & $\mathrm{IL}-8$ & Up & In women only [266] \\
\hline & IL-12 & -correlation with symptoms & Men only [266] \\
\hline & TNF- $\alpha$ & $\begin{array}{l}\text { Up or }+ \text { correlation with } \\
\text { symptoms }\end{array}$ & Did not differentiate sex [265] In women only [266] \\
\hline & adiponectin & Down & In women only [266] \\
\hline & Insulin & Up & Men and women, higher in women [271] \\
\hline & Leptin & Up & In women only/higher in depressed women than men [266] \\
\hline & White blood cells & Up & Men and Women [272] \\
\hline & Monocytes & Up & Men only [272] \\
\hline & MMP-9 & Up & Men and Women, higher in women [271] \\
\hline \multirow[t]{3}{*}{ Bipolar } & CRP & Up + correlation in manic stage & Did not differentiate by sex $[273,274]$ \\
\hline & IL-6 & Up: higher in manic stage & Did not differentiate by sex [275] \\
\hline & IL-18 & Up in depressed stage & Did not differentiate by sex [275] \\
\hline & $\mathrm{IL}-1 \alpha$ & Up & Did not differentiate sex [277] \\
\hline & $\mathrm{IL}-1 \beta$ & Up & Did not differentiate sex [277] \\
\hline & IL-2 & Up & Did not differentiate sex [277] \\
\hline & $\mathrm{IL}-4$ & Up & Did not differentiate sex [277] \\
\hline & IL-6 & Up & Did not differentiate sex [277] Men and women $[276,278]$ \\
\hline & IL-7 & Up & Did not differentiate sex [277] \\
\hline & IL-8 & Up & Did not differentiate sex [277] \\
\hline & IL-10 & Up & Did not differentiate sex [277] \\
\hline & IL-12(p40 \& p70) & Up & Did not differentiate sex [277] \\
\hline & IL-13 & Up & Did not differentiate sex [277] \\
\hline & IL-15 & Up & Did not differentiate sex [277] \\
\hline & IP-10 & Up & Did not differentiate sex [277] \\
\hline & Mip-1 $\alpha$ & Up & Did not differentiate sex [277] \\
\hline & TNF- $\alpha$ & Up & Did not differentiate sex [277], Women [276] \\
\hline \multirow[t]{4}{*}{ Anxiety } & $\mathrm{IL}-1 \beta$ & + correlation & Women only [267] \\
\hline & IL-10 & + correlation & Women only [267] \\
\hline & $\mathrm{IL}-17$ & -correlation & Women only [267] \\
\hline & TGF- $\beta 1$ & -correlation & Men and women [267] \\
\hline
\end{tabular}


Aspirin has a higher bioavailability in women than in men, and oral contraceptives reverse these metabolic sex differences [248].

\section{KETAMINE}

Ketamine is an N-methyl-D-aspartate receptor antagonist that has rapid and sustained antidepressant effects [249], which is especially important as most pharmacological treatments for depression requires weeks of administration. Ketamine reduced depression-like symptoms in mice by attenuating stressassociated increases in pro-inflammatory cytokines, reactive microglia, and expression of the pattern recognition receptors in the hippocampus [250]. A similar study of chronic unpredictable mild stress in rats also reported a decrease in inflammatory cytokines in the hippocampus, including IL- $6, \mathrm{IL}-1 \beta$, and TNF- $a$ [251]. However, in mice that were not exposed to stress, ketamine had the opposite effect on pro-inflammatory cytokines in the hippocampus, and a single dose was sufficient to increase protein levels of IL-6, IL-1 $\beta$, and TNF- $a$ [252].

A recent study examined which cytokines changed in patients with treatment-resistant depression (Table 1) following successful or unsuccessful response to ketamine treatment [226]. In an attempt to discern biomarkers that indicate the effectiveness of ketamine, they found that IL-6, IL-1a, granulocyte colonystimulating factor, IL-13, and interferon- $\gamma$-induced protein 10 were all reduced compared with the baseline levels within $4 \mathrm{~h}$ of ketamine treatment, even though there were no differences between baseline levels and circulating levels $24 \mathrm{~h}$ after ketamine treatment. At $24 \mathrm{~h} \quad \mathrm{LL}-7$ was increased, and $\mathrm{IL}-8$ and the heterodimer of platelet-derived growth factor were decreased. By further dividing the ketamine patients into responders and non-responders using changes in their MADRS scores before and after treatment, they found that fibroblast growth factor (FGF) 2 and IL-1RA were significantly lower in ketamine responders. In particular, FGF-2 strongly negatively correlated with changes in MADRS scores. This study underscores the need to examine more than just baseline levels of cytokines to understand their complex relationship to depression.

Depression-like behavior in male congenitally learned helpless rats is dependent on burst activity in the lateral habenula (LHb), a brain region involved in the pathophysiology of MDD that inhibits reward centers [253]. Ketamine infusion directly into the LHb was sufficient to rapidly rescue the depression-like behaviors [253]. The astroglial potassium channel Kir4.1 was upregulated the LHb of both learned helpless rats and in rats following LPS treatment. Viral overexpression of Kir4.1 in astrocytes of the LHb of wild-type male mice induced severe depression-like behaviors [254]. Viral knockdown of Kir4.1 reduced depression-like behaviors in male rats, and resulted in an overall increase in the depolarization of neighboring neurons in the $\mathrm{LHb}$ [254]. These data provide strong evidence for the role of astrocytic regulation of neuronal signaling in depression, and suggest a novel mechanism for ketamine's rapid antidepressant effects in male rodents.

Data from animal models suggest that there may be sex differences in sensitivity to dose of ketamine and the biological mechanisms through which it mediates the antidepressant response. Ketamine had long-lasting antidepressant effects in male mice exposed to chronic mild stress for 5 weeks, but not females. Females instead were more sensitive to acute effects of ketamine at both $30 \mathrm{~min}$ and $24 \mathrm{~h}$ [255]. Females responded to doses of ketamine that were not effective in males suggesting increased sensitivity [256-258]. Stage of the estrous cycle contributed to a variable female behavioral and biochemical response to ketamine [258]. Females were more sensitive to low doses of ketamine when in proestrus, an effect that was mediated by both isoforms of the estrogen receptor. Treatment of proestrus females with ketamine resulted in changes in the protein kinase $B$ and $\mathrm{Ca}^{2+} /$ calmodulin-dependent protein kinase pathways in pre- frontal cortex and hippocampus that only occurred in males or females in diestrus at higher doses [258]. The mechanism of by which ketamine affects behavior may also be different in males and females. Ketamine has been proposed to act, in part, by changing post-synaptic plasticity including dendritic spine density [259]. Males exposed to chronic stress had decreased spine density in the medial pre-frontal cortex, which along with behavioral deficits, were rescued by treatment with ketamine. Although ketamine reversed effects of stress on behavior in females, it did not rescue effects on spine density, indicating a different mechanism of action for the antidepressant properties of the drug [256]. More data from studies on humans and animals are needed to understand the ability of ketamine to treat depression in males and females and how this relates to immune changes associated with the actions of ketamine.

\section{TARGETING THE IMMUNE SYSTEM TO TREAT MOOD DISORDERS}

Cytokine antibody therapy has been demonstrated in multiple studies to be an effective treatment for depression in patients with increased peripheral measures of inflammation, [260]. Infliximab is a monoclonal antibody against TNF-a. Treatment with infliximab was successful in decreasing depression symptoms in patients that had higher baseline TNF- $a$, and TNF- $a$ receptor concentrations, as well as a baseline high CRP defined as $>5 \mathrm{mg} / \mathrm{L}$ [154]. These were the first data to suggest that the basal inflammatory state of a person predicts their response to immune manipulation. Going forward, many immunotherapy studies for mood disorders are focused on testing specifically in patients that have elevated CRP. A recent study examined the ability of IL-6-neutralizing antibodies to treat feelings of depressed mood and anhedonia in patients undergoing treatment for rheumatoid arthritis and Castleman's disease [261]. IL-6 antibody treatment improved mood and anhedonia, and effects were only partially owing to improvement in disease symptoms. There was a correlation between basal levels of the soluble IL- 6 receptor, which has proinflammatory properties [62] and improvement of depressive symptoms when treated with the antibody.

A new pre-clinical study aims to reverse depression-like behaviors by targeting both the periphery and the brain [223]. Two phytochemicals were identified that acted together to suppress increased IL- 6 in the periphery and target epigenetic modulation of Rac1, a gene involved in plasticity in the brain. When given to animals that had received bone marrow transplants from stress susceptible mice and were subsequently exposed to a subthreshold stress, it blocked effects on behavior and reduced all inflammatory effects on cytokines and innate immune cells to levels of unstressed controls. Treatment of these compounds following social defeat stress reversed avoidance behavior and anhedonia in previously stress susceptible mice. The compound was also able to block the effects of variable stress in both male and female mice indicating it works in both sexes and on different types of stressors [223].

\section{FUTURE RESEARCH DIRECTIONS}

Targeting the peripheral immune system holds great promise as a new form of therapy to treat mood disorders. The obvious benefit is that drugs do not need to cross the BBB in order to produce effects. Given the number of cells in the immune system that phagocytize and are implicated in the stress response, cell type-specific drug delivery could be done through infusion and designed to be activated when ingested. There are currently a number of nanoparticle drug delivery systems being developed to deliver chemotherapy drugs or targeting antigen-presenting cells to deliver vaccines [262]. Lipid encapsulation of small interfering RNAs are deliverable to 
macrophages to knockdown the inflammatory response of monocytes and dendritic cells in vivo [263], and this type of delivery system could be adapted to alter molecular mechanisms within immune cells that over respond to activation from stress. Additional studies are examining the promise of transplanting engineered cells, encapsulated in order to prevent rejection, to treat diabetes, blood disease, and cancer [264]. Engineering encapsulated pluripotent bone marrow stem cells could also be used to target the development of an entire immune system. Alternatively, specific cell types could be reprogramed to respond less to stress and replaced. The first generation of immune-based treatments currently being tested for antidepressant efficacy act by suppressing specific cytokines and immunosuppression is not a long-term solution. Ideally, combining what we learn from both clinical and pre-clinical studies, we will be able to find targets to modulate within specific immune cells and harness this next generation of technology to temper biological triggers of mood disorders.

Clearly, much more work is needed to understand how sex differences in immune function contribute to the sex differences reported in mood disorders. There is lack of understanding how the sex of a subject's immune system contributes to its response to stress in pre-clinical studies. Examinations of sex differences in immune function at more restricted age ranges are also needed for both clinical and pre-clinical work. It is imperative that we find new cell type-specific ways to examine immune response within the brain and examine sex as a variable for studies of central inflammation. We need studies that cross the barriers of basic and clinical research, examine peripheral and central targets, and include sex as a variable, to really understand how immune activation is related to mood disorders. The future success of our biomarker studies and treatment options depend upon taking this personalized approach to research.

\section{ACKNOWLEDGEMENTS}

We thank Mariya Tsyglakova for her assistance with editing the manuscript. This work was funded by a NARSAD Young Investigator award from the Brain and Behavior research foundation to $\mathrm{GEH}$.

\section{ADDITIONAL INFORMATION}

Competing interests: There are no competing interests in relation to the work described in the manuscript.

Publisher's note: Springer Nature remains neutral with regard to jurisdictional claims in published maps and institutional affiliations.

\section{REFERENCES}

1. Will TR, Proaño SB, Thomas AM, Kunz LM, Thompson KC, Ginnari LA, et al. Problems and progress regarding sex bias and omission in neuroscience research. Eneuro. 2017;4:ENEURO.0278-17.2017

2. Zucker I, Beery AK. Males still dominate animal studies. Nature. 2010;465:690.

3. Abdi F, Mobedi H, Mosaffa N, Dolatian M, Ramezani Tehrani F. Effects of hormone replacement therapy on immunological factors in the postmenopausal period. Climacteric. 2016;19:234.

4. Paganelli R, lorio ADi, Cherubini A, Lauretani F, Mussi C, Volpato S, et al. Frailty of older age: the role of the endocrine - immune interaction. Curr Pharm Des. 2006;12:3147-59.

5. Giefing-Kröll C, Berger P, Lepperdinger G, Grubeck-Loebenstein B. How sex and age affect immune responses, susceptibility to infections, and response to vaccination. Aging Cell. 2015;14:309-21.

6. Gubbels Bupp MR. Sex, the aging immune system, and chronic disease. Cell Immunol. 2015;294:102-10.

7. Kessler RC. Epidemiology of women and depression. J Affect Disord. 2003;74:5-13.

8. Kessler RC, Demler O, Frank RG, Olfson M, Pincus HA, Walters EE, et al. Prevalence and treatment of mental disorders, 1990 to 2003. N Engl J Med. 2005;352:2515-23.
9. Kessler RC, McGonagle KA, Swartz M, Blazer DG, Nelson CB. Sex and depression in the National Comorbidity Survey I: lifetime prevalence, chronicity and recurrence. J Affect Disord. 1993;29:85-96.

10. Parker G, Brotchie H. Gender differences in depression. Int Rev Psychiatry. 2010;22:429-36.

11. Weissman MM, Bland R, Joyce PR, Newman S, Wells JE, Wittchen HU. Sex differences in rates of depression: cross-national perspectives. J Affect Disord. 1993;29:77-84.

12. Weissman MM, Klerman GL. Sex differences and the epidemiology of depression. Arch Gen Psychiatry. 1977;34:98-111.

13. Kornstein SG, Schatzberg AF, Thase ME, Yonkers KA, McCullough JP, Keitner Gl, et al. Gender differences in chronic major and double depression. J Affect Disord. 2000;60:1-11.

14. Scott KM. Sex differences in the disability associated with mental disorders. Curr Opin Psychiatry. 2011;24:331-5.

15. Zagni E, Simoni L, Colombo D. Sex and gender differences in central nervous system-related disorders. Neurosci J. 2016;2016:1-13.

16. Zetin M, Sklansky GJ, Cramer M. Sex differences in inpatients with major depression. J Clin Psychiatry. 1984;45:257-9.

17. Marcus SM, Kerber KB, Rush AJ, Wisniewski SR, Nierenberg A, Balasubramani GK, et al. Sex differences in depression symptoms in treatment-seeking adults: confirmatory analyses from the sequenced treatment alternatives to relieve depression study. Compr Psychiatry. 2008;49:238-46.

18. Marcus SM, Young EA, Kerber KB, Kornstein SG, Farabaugh AH, Mitchell J, et al. Gender differences in depression: findings from the $S T A R^{*} D$ study. J Affect Disord. 2005;87:141-50.

19. Frank E, Carpenter LL, Kupfer DJ. Sex differences in recurrent depression: are there any that are significant? Am J Psychiatry. 1988;145:41-45.

20. Halbreich U, Kahn LS. Atypical depression, somatic depression and anxious depression in women: are they gender-preferred phenotypes? J Affect Disord. 2007;102:245-58.

21. Kapfhammer H-P. Somatic symptoms in depression. Dialogues Clin Neurosci. 2006;8:227-39.

22. Diflorio A, Jones I. Is sex important? Gender differences in bipolar disorder. Int Rev Psychiatry. 2010;22:437-52.

23. Baldassano CF, Marangell LB, Gyulai L, Ghaemi SN, Joffe H, Kim DR, et al. Gender differences in bipolar disorder: Retrospective data from the first 500 STEP-BD participants. Bipolar Disord. 2005;7:465-70.

24. Schneck CD, Miklowitz DJ, Miyahara S, Araga M, Wisniewski S, Gyulai L, et al. The prospective course of rapid-cycling bipolar disorder: findings from the STEP-BD. Am J Psychiatry. 2008;165:370-7.

25. Cassano GB, Akiskal HS, Savino M, Musetti L, Perugi G. Proposed subtypes of bipolar II and related disorders: with hypomanic episodes (or cyclothymia) and with hyperthymic temperament. J Affect Disord. 1992;26:127-40.

26. Hendrick V, Altshuler LL, Gitlin MJ, Delrahim S, Hammen C, Gender and bipolar illness. J Clin Psychiatry. 2000;61:393-6.

27. Rasgon N, Bauer M, Grof P, Gyulai L, Elman S, Glenn T, et al. Sex-specific selfreported mood changes by patients with bipolar disorder. J Psychiatr Res. 2005;39:77-83

28. Kupka RW, Luckenbaugh DA, Post RM, Leverich GS, Nolen WA. Rapid and nonrapid cycling bipolar disorder: a meta-analysis of clinical studies. J Clin Psychiatry. 2003;64:1483-94.

29. Leibenluft E. Women and bipolar disorder: an update. Bull Menn Clin. 2000;64:5-17.

30. Tondo L, Baldessarini RJ. Rapid cycling in women and men with bipolar manicdepressive disorders. Am J Psychiatry. 1998;155:1434-6.

31. Kawa I, Carter JD, Joyce PR, Doughty CJ, Framtpon CM, Wells JE, et al. Gender differences in bipolar disorder: age of onset, course, comorbidity, and symptom presentation. Bipolar Disord. 2005;7:119-25.

32. Benazzi F. The role of gender in depressive mixed state. Psychopathology. 2003;36:213-7.

33. Frye Ma, Altshuler LL, McElroy SL, Suppes T, Keck PE, Denicoff K, et al. Gender differences in prevalence, risk, and clinical correlates of alcoholism comorbidity in bipolar disorder. Am J Psychiatry. 2003;160:883-9.

34. Suominen $K$, Mantere $O$, Valtonen $H$, Arvilommi $P$, Leppämäki S, Isometsä $E$. Gender differences in bipolar disorder type i and II. Acta Psychiatr Scand. 2009;120:464-73.

35. Benedetti A, Fagiolini A, Casamassima F, Mian MS, Adamovit A, Musetti L, et al. Gender differences in bipolar disorder type 1. J Nerv Ment Dis. 2007;195:93-96.

36. Kennedy BL, Dhaliwal N, Pedley L, Sahner C, Greenberg R, Manshadi MS. Posttraumatic stress disorder in subjects with schizophrenia and bipolar disorder. J Ky Med Assoc. 2002;100:395-9.

37. Marsh WK, Templeton A, Ketter TA, Rasgon NL. Increased frequency of depressive episodes during the menopausal transition in women with bipolar disorder: Preliminary report. J Psychiatr Res. 2008;42:247-51. 
38. Blehar MC, DePaulo JR, Gershon ES, Reich T, Simpson SG, Nurnberger JI. Women with bipolar disorder: findings from the NIMH Genetics Initiative sample. Psychopharmacol Bull. 1998;34:239-43.

39. Freeman MP, Smith KW, Freeman SA, McElroy SL, Kmetz GE, Wright R, et al. The impact of reproductive events on the course of bipolar disorder in women. J Clin Psychiatry. 2002;63:284-7.

40. Jones I, Craddock N. Bipolar disorder and childbirth: the importance of recognising risk. Br J Psychiatry. 2005;186:453-4.

41. Jones L, Scott J, Cooper C, Forty L, Smith KG, Sham P, et al. Cognitive style, personality and vulnerability to postnatal depression. $\mathrm{Br} J$ Psychiatry. 2010;196:200-5.

42. Munk-Olsen T, Laursen TM, Pedersen CB, Mors O, Mortensen PB. New parents and mental disorders. JAMA. 2006;296:2582.

43. Kessler RC, Foster CL, Saunders WB, Stang PE. Social consequences of psychiatric disorders, I: educational attainment. Am J Psychiatry. 1995;152: 1026-32.

44. Kessler RC, Mcgonagle KA, Zhao S, Nelson CB, Hughes M, Eshleman S, et al. Lifetime and 12-month prevalence of DSM-III-R psychiatric disorders in the United States. Arch Gen Psychiatry. 1994;51:8-19.

45. Gater R, Tansella M, Korten A, Tiemens B, Mavreas V, Olatawura M. Sex differences in the prevalence and detection of depressive and anxiety disorders in general health care settings. Arch Gen Psychiatry. 1998;55: 405-13.

46. Ruscio AM, Stein DJ, Chiu WT, Kessler RC. The epidemiology of obsessivecompulsive disorder in the National Comorbidity Survey Replication. Mol Psychiatry. 2010;15:53-63.

47. Weissman MM, Bland RC, Canino GJ, Greenwald S, Hwu HG, Lee CK, et al. The cross national epidemiology of obsessive compulsive disorder. The Cross National Collaborative Group. J Clin Psychiatry. 1994;55:5-10.

48. Xu Y, Schneier F, Heimberg RG, Princisvalle K, Liebowitz MR, Wang S, et al. Gender differences in social anxiety disorder: Results from the national epidemiologic sample on alcohol and related conditions. J Anxiety Disord. 2012;26: 12-19.

49. Altemus M, Sarvaiya N, Neill Epperson C. Sex differences in anxiety and depression clinical perspectives. Front Neuroendocrinol. 2014;35:320-30.

50. Narrow WE, Rae DS, Robins LN, Regier DA. Revised prevalence estimates of mental disorders in the United states. Arch Gen Psychiatry. 2002; 59:115.

51. Roberts A, Gilman S, Breslau J, Breslau N, Koenen K. Race/ethnic differences in exposure to traumatic events, development of post-traumatic stress disorder, and treatment- seeking for post-traumatic stress disorder in the United States. Psychol Med. 2011;41:71-83.

52. Tolin DF, Foa EB. Sex differences in trauma and posttraumatic stress disorder: a quantitative review of 25 years of research. Psychol Bull. 2006;132: 959-92.

53. Crum-Cianflone NF, Jacobson I. Gender differences of postdeployment posttraumatic stress disorder among service members and veterans of the Iraq and Afghanistan conflicts. Epidemiol Rev. 2014;36:5-18.

54. Freedman SA, Gluck N, Tuval-Mashiach R, Brandes D, Peri T, Shalev AY. Gender differences in responses to traumatic events: a prospective study. J Trauma Stress. 2002;15:407-13.

55. De Bellis MD, Keshavan MS. Sex differences in brain maturation in maltreatment-related pediatric posttraumatic stress disorder. Neurosci Biobehav Rev. 2003;27:103-17.

56. Samplin E, Ikuta T, Malhotra AK, Szeszko PR, DeRosse P. Sex differences in resilience to childhood maltreatment: Effects of trauma history on hippocampal volume, general cognition and subclinical psychosis in healthy adults. J Psychiatr Res. 2013;47:1174-9.

57. Ressler KJ, Mercer KB, Bradley B, Jovanovic T, Mahan A, Kerley K, et al. Posttraumatic stress disorder is associated with PACAP and the PAC1 receptor. Nature. 2011;470:492-7.

58. Turner MD, Nedjai B, Hurst T, Pennington DJ. Cytokines and chemokines: at the crossroads of cell signalling and inflammatory disease. Biochim Biophys Acta. 2014;1843:2563-82.

59. Coutinho $A E$, Chapman KE. The anti-inflammatory and immunosuppressive effects of glucocorticoids, recent developments and mechanistic insights. Mol Cell Endocrinol. 2011;335:2-13.

60. Turvey SE, Broide DH. Innate immunity. J Allergy Clin Immunol. 2010;125: S24-32.

61. Bonilla FA, Oettgen HC. Adaptive immunity. J Allergy Clin Immunol. 2010;125: S33-40.

62. Hodes GE, Ménard C, Russo SJ. Integrating Interleukin-6 into depression diagnosis and treatment. Neurobiol Stress. 2016;4:15-22.

63. Klein SL. Immune cells have sex and so should journal articles. Endocrinology. 2012;153:2544-50
64. Nalbandian G, Kovats S. Understanding sex biases in immunity: effects of estrogen on the differentiation and function of antigen-presenting cells. Immunol Res. 2005;31:91-106.

65. Zuk M. Disease, endocrine-immune interactions, and sexual selection. Ecology. 1996;77:1037-42.

66. Bouman A, Jan Heineman M, Faas MM. Sex hormones and the immune response in humans. Hum Reprod Update. 2005;11:411-23.

67. Bianchi I, Lleo A, Gershwin ME, Invernizzi P. The $X$ chromosome and immune associated genes. J Autoimmun. 2012;38:J187-92.

68. Qin S, Rottman JB, Myers $P$, Kassam N, Weinblatt $M$, Loetscher $M$, et al. The chemokine receptors CXCR3 and CCR5 mark subsets of T cells associated with certain inflammatory reactions. J Clin Invest. 1998;101:746-54.

69. Wang J, Syrett CM, Kramer MC, Basu A, Atchison ML, Anguera MC (2016). Unusual maintenance of $X$ chromosome inactivation predisposes female lymphocytes for increased expression from the inactive $X$. Proc Natl Acad Sci. 2016;113:E2029-38

70. Libert $C$, Dejager $L$, Pinheiro I. The $X$ chromosome in immune functions: when a chromosome makes the difference. Nat Rev Immunol. 2010;10:594-604.

71. Pinheiro I, Dejager L, Libert C. X-chromosome-located microRNAs in immunity: might they explain male/female differences?: the $X$ chromosome-genomic context may affect X-located miRNAs and downstream signaling, thereby contributing to the enhanced immune response of females. BioEssays. 2011;33: 791-802.

72. Case LK, Wall EH, Dragon JA, Saligrama N, Krementsov DN, Moussawi M, et al. The $y$ chromosome as a regulatory element shaping immune cell transcriptomes and susceptibility to autoimmune disease. Genome Res. 2013;23: 1474-85.

73. Arnold AP, Chen X. What does the "four core genotypes" mouse model tell us about sex differences in the brain and other tissues? Front Neuroendocrinol. 2009;30:1-9.

74. Palaszynski KM, Smith DL, Kamrava S, Burgoyne PS, Arnold AP, Voskuhl RR. A yin-yang effect between sex chromosome complement and sex hormones on the immune response. Endocrinology. 2005;146:3280-5.

75. de Kloet ER, Otte C, Kumsta R, Kok L, Hillegers MHJ, Hasselmann H et al. Stress and depression: a crucial role of the mineralocorticoid receptor. J Neuroendocrinol. 2016;28:1-12.

76. Keselman A, Heller N. Estrogen signaling modulates allergic inflammation and contributes to sex differences in asthma. Front Immunol. 2015;6:568.

77. McMurray RW, Suwannaroj S, Ndebele K, Jenkins JK. Differential effects of sex steroids on T and B cells: modulation of cell cycle phase distribution, apoptosis and bcl-2 protein levels. Pathobiology. 2001;69:44-58.

78. Shiau HJ, Aichelmann-Reidy ME, Reynolds MA, Influence of sex steroids on inflammation and bone metabolism. Periodontol 2000. 2014;64:81-94.

79. Trigunaite A, Dimo J, Jørgensen TN. Suppressive effects of androgens on the immune system. Cell Immunol. 2015;294:87-94.

80. Erlandsson MC, Ohlsson C, Gustafsson JÅ, Carlsten H. Role of oestrogen receptors alpha and beta in immune organ development and in oestrogenmediated effects on thymus. Immunology. 2001;103:17-25.

81. Hemmi $H$, Akira S. TLR signalling and the function of dendritic cells. Chem Immunol Allergy. 2005;86:120-35.

82. Ghosh S, Klein RS. Sex drives dimorphic immune responses to viral infections. J Immunol. 2017;198:1782-90

83. Rainville JR, Tsyglakova M, Hodes GE, Deciphering sex differences in the immune system and depression. Front Neuroendocrinol. 2018 (In press).

84. Young NA, Wu LC, Burd CJ, Friedman AK, Kaffenberger BH, Rajaram MVS, et al. Estrogen modulation of endosome-associated toll-like receptor 8: an IFNaindependent mechanism of sex-bias in systemic lupus erythematosus. Clin Immunol. 2014;151:66-77.

85. Luster MI, Hayes HT, Korach K, Tucker AN, Dean JH, Howard MIL, et al. Estrogen immunosuppression is regulated through estrogenic responses in the thymus. J Immunol. 1984;133:110-6.

86. Pelekanou V, Kampa M, Kiagiadaki F, Deli A, Theodoropoulos P, Agrogiannis G, et al. Estrogen anti-inflammatory activity on human monocytes is mediated through cross-talk between estrogen receptor ERa36 and GPR30/GPER1. J Leukoc Biol. 2014;31:333-47.

87. Oertelt-Prigione S. Immunology and the menstrual cycle. Autoimmun Rev. 2012;11:A486-92.

88. Neigh GN, Nemeth $C L$, Rowson SA. Sex differences in immunity and inflammation: implications for brain and behavior. In: Shansky RM editor. Sex Differences in the Central Nervous System. Elsevier; 2015. p.1-26.

89. Furman D, Hejblum BP, Simon N, Jojic V, Dekker CL, Thiébaut R, et al. Systems analysis of sex differences reveals an immunosuppressive role for testosterone in the response to influenza vaccination. Proc Natl Acad Sci. 2014;111:869-74.

90. Dhabhar FS, McEwen BS. Stress-induced enhancement of antigen-specific cellmediated immunity. J Immunol. 1996;156:2608-15. 
91. Dhabhar FS, Miller AH, McEwen BS, Spencer RL. Effects of stress on immune cell distribution. Dynamics and hormonal mechanisms. J Immunol. 1995;154: 5511-27.

92. Dhabhar FS, McEwen BS. Enhancing versus suppressive effects of stress hormones on skin immune function. Proc Natl Acad Sci. 1999;96:1059-64.

93. Dhabhar FS, McEwen BS. Acute stress enhances while chronic stress suppresses cell-mediated immunity in vivo: a potential role for leukocyte trafficking. Brain Behav Immun. 1997;11:286-306.

94. Ramamoorthy S, Cidlowski JA. Corticosteroids. mechanisms of action in health and disease. Rheum Dis Clin North Am. 2016;42:15-31.

95. Benea NC, Alcaidea $P$, Wortis HH, Jaffe IZ. Mineralocorticoid receptors in immune cells: emerging role in cardiovascular disease. Steroids. 2014;0:38-45.

96. McKim DB, Weber MD, Niraula A, Sawicki CM, Liu X, Jarrett BL et al. Microglial recruitment of IL-1 $\beta$-producing monocytes to brain endothelium causes stressinduced anxiety. Mol Psychiatry. 2017; https://doi.org/10.1038/mp.2017.64.

97. Wohleb ES, McKim DB, Sheridan JF, Godbout JP. Monocyte trafficking to the brain with stress and inflammation: a novel axis of immune-to-brain communication that influences mood and behavior. Front Neurosci. 2015; 9:1-17.

98. Niraula A, Wang Y, Godbout JP, Sheridan JF. Corticosterone production during repeated social defeat causes monocyte mobilization from the bone marrow, glucocorticoid resistance and neurovascular adhesion molecule expression. J Neurosci. 2018;38:2568-17.

99. Holsboer-Trachsler E, Stohler R, Hatzinger M. Repeated administration of the combined dexamethasone-human corticotropin releasing hormone stimulation test during treatment of depression. Psychiatry Res. 1991:38:163-71.

100. Baumeister D, Lightman SL, Pariante CM. The interface of stress and the HPA axis in behavioural phenotypes of mental illness. Behav Neurobiol Stress Disord. 2014;18:14-34.

101. Burke HM, Davis MC, Otte C, Mohr DC. Depression and cortisol responses to psychological stress: a meta-analysis. Psychoneuroendocrinology. 2005;30: 846-56.

102. Holsen LM, Lancaster K, Klibanski A, Whitfield-Gabrieli S, Cherkerzian S, Buka S et al. HPA axis hormone modulation of stress response circuitry activity in women with remitted major depression. Neuroscience. 2013;250:732-42.

103. Ahrens T, Deuschle M, Krumm B, Van Der Pompe G, Den Boer JA, Lederbogen F. Pituitary-adrenal and sympathetic nervous system responses to stress in women remitted from recurrent major depression. Psychosom Med. 2008;70:461-7.

104. de Kloet CS, Vermetten E, Geuze E, Kavelaars A, Heijnen CJ, Westenberg HGM. Assessment of HPA-axis function in posttraumatic stress disorder: Pharmacological and non-pharmacological challenge tests, a review. J Psychiatr Res. 2006;40:550-67.

105. Agarwal SK, Marshall GD. Glucocorticoid-induced type 1/type 2 cytokine alterations in humans: a model for stress-related immune dysfunction. J Interf Cytokine Res. 1998;18:1059-68.

106. Pariante $\mathrm{CM}$, Pearce $\mathrm{BD}$, Pisell TL, Sanchez $\mathrm{Cl}$, Po $\mathrm{C}$, Su C, et al. The proinflammatory cytokine, interleukin-1a, reduces glucocorticoid receptor translocation and function. Endocrinology. 1999;140:4359-66.

107. Kudielka BM, Kirschbaum C. Sex differences in HPA axis responses to stress: a review. Biol Psychol. 2005;69:113-32.

108. Kirschbaum C, Wüst S, Hellhammer D. Consistent sex differences in cortisol responses to psychological stress. Psychosom Med. 1992;54:648-57.

109. Rohleder N, Schommer NC, Hellhammer DH, Engel R, Kirschbaum C. Sex differences in glucocorticoid sensitivity of proinflammatory cytokine production after psychosocial stress. Psychosom Med. 2001;63:966-72.

110. Solomon MB, Furay AR, Jones K, Packard AEB, Packard BA, Wulsin AC, et al. Deletion of forebrain glucocorticoid receptors impairs neuroendocrine stress responses and induces depression-like behavior in males but not females. Neuroscience. 2012;203:135-43.

111. Solomon MB, Loftspring $M$, De Kloet AD, Ghosal S, Jankord R, Flak JN, et al. Neuroendocrine function after hypothalamic depletion of glucocorticoid receptors in male and female mice. Endocrinology. 2015;156:2843-53.

112. Bangasser D, Reyes B, Piel D, Garachh V, Zhang X-Y, Plona Z, et al. Increased vulnerability of the brain norepinephrine system of females to corticotropinreleasing factor overexpression. Mol Psychiatry. 2012;18:166-73.

113. Hodes GE, Kana V, Menard C, Merad M, Russo SJ. Neuroimmune mechanisms of depression. Nat Neurosci. 2015;18:1386-93.

114. Barnes JN. Sex specific factors regulating pressure and flow. Exp Physiol. 2017;11:1385-92.

115. Casey DP, Curry TB, Joyner MJ, Charkoudian N, Hart EC. Relationship between muscle sympathetic nerve activity and aortic wave reflection characteristics in young men and women. Hypertension. 2011;57:421-7.

116. Kneale BJ, Chowienczyk PJ, Brett SE, Coltart DJ, Ritter JM. Gender differences in sensitivity to adrenergic agonists of forearm resistance vasculature. J Am Coll Cardiol. 2000;36:1233-8.
117. Freedman RR, Sabharwal SC, Desai N. Sex differences in peripheral vascular adrenergic receptors. Circ Res. 1987;61:581-5.

118. Hart EC, Charkoudian N, Wallin BG, Curry TB, Eisenach J, Joyner MJ. Sex and ageing differences in resting arterial pressure regulation: the role of the betaadrenergic receptors. J Physiol. 2011;589:5285-97.

119. Balhara YS, Verma R, Gupta C. Gender differences in stress response: role of developmental and biological determinants. Ind Psychiatry J. 2012;20:4.

120. Head JR, Griffin WST. Functional capacity of solid tissue transplants in the brain: evidence for immunological privilege. Proc R Soc London B Biol Sci. 1985;224: 375-87.

121. Louveau A, Harris TH, Kipnis J. Revisiting the mechanisms of CNS immune privilege. Trends Immunol. 2015;36:569-77.

122. Louveau A, Kipnis J. Sex, gut, and microglia. Dev Cell. 2018:44:137-8.

123. Louveau A, Smirnov I, Keyes TJ, Eccles JD, Rouhani SJ, Peske JD, et al. Structural and functional features of central nervous system lymphatic vessels. Nature. 2015;523:337-41.

124. Wohleb ES, Powell ND, Godbout JP, Sheridan JF. Stress-induced recruitment of bone marrow-derived monocytes to the brain promotes anxiety-like behavior. J Neurosci. 2013;33:13820-33.

125. Pan W, Stone KP, Hsuchou H, Manda VK, Zhang Y, Kastin AJ. Cytokine signaling modulates blood-brain barrier function. Curr phar. 2011;17:3729-40.

126. Banks W. Blood-brain barrier transport of cytokines: a mechanism for neuropathology. Curr Pharm Des. 2005;11:973-84.

127. Menard C, Pfau ML, Hodes GE, Kana V, Wang VX, Bouchard S, et al. Social stress induces neurovascular pathology promoting depression. Nat Neurosci. 2017;20: 1752-60.

128. Golden SA, Covington HE III, Berton O, Russo SJ. A standardized protocol for repeated social defeat stress in mice. Nat Protoc. 2011;6:1183-91.

129. Krishnan V, Han M, Graham DL, Berton O, Renthal W, Russo SJ, et al. Molecularadaptations underlying susceptibility and resistance to social defeat in brain reward regions. Cell. 2007;131:391-404.

130. Cheng Y, Desse S, Martinez A, Worthen RJ, Jope RS, Beurel E. TNFa disrupts blood brain barrier integrity to maintain prolonged depressive-like behavior in mice. Brain Behav Immun. 2018;69:556-67.

131. Ataka K, Asakawa A, Nagaishi K, Kaimoto K, Sawada A, Hayakawa Y, et al. Bone marrow-derived microglia infiltrate into the paraventricular nucleus of chronic psychological stress-loaded mice. PLoS ONE. 2013;8:1-14.

132. Engler H, Bailey MT, Engler A, Sheridan JF. Effects of repeated social stress on leukocyte distribution in bone marrow, peripheral blood and spleen. J Neuroimmunol. 2004;148:106-15.

133. Powell ND, Sloan EK, Bailey MT, Arevalo JMG, Miller GE, Chen E, et al. Social stress up-regulates inflammatory gene expression in the leukocyte transcriptome via $\beta$-adrenergic induction of myelopoiesis. Proc Natl Acad Sci. 2013;110:16574-9.

134. Wohleb ES, Godbout JP. Basic aspects of the immunology of neuroinflammation. Inflamm Psychiatry. 2013;28:1-19.

135. Wohleb ES, McKim DB, Shea DT, Powell ND, Tarr AJ, Sheridan JF, et al. Re-establishment of anxiety in stress-sensitized mice is caused by monocyte trafficking from the spleen to the brain. Biol Psychiatry. 2014;75:970-81.

136. Kelly JR, Kennedy PJ, Cryan JF, Dinan TG, Clarke G, Hyland NP. Breaking down the barriers: the gut microbiome, intestinal permeability and stressrelated psychiatric disorders. Front Cell Neurosci. 2015;9:392.

137. Doran KS, Banerjee A, Disson O, Lecuit M. Concepts and mechanisms: crossing host barriers. Cold Spring Harb Perspect Med. 2013;3:1-20.

138. Wiley NC, Dinan TG, Ross RP, Stanton C, Clarke G, Cryan JF. The microbiota-gutbrain axis as a key regulator of neural function and the stress response: Implications for human and animal health. J Anim Sci. 2017;95:3225-46.

139. Sudo N, Chida Y, Aiba Y, Sonoda J, Oyama N, Yu XN, et al. Postnatal microbial colonization programs the hypothalamic-pituitary-adrenal system for stress response in mice. J Physiol. 2004;558:263-75.

140. Fung TC, Olson CA, Hsiao EY. Interactions between the microbiota, immune and nervous systems in health and disease. Nat Neurosci. 2017:20:145-55.

141. Maes $M$, Kubera $M$, Leunis J-C. The gut-brain barrier in major depression: intestinal mucosal dysfunction with an increased translocation of LPS from gram negative enterobacteria (leaky gut) plays a role in the inflammatory pathophysiology of depression. Neuro Endocrinol Lett. 2008;29: 117-24.

142. Kelly JR, Borre Y, O' Brien C, Patterson E, Aidy SEl, Deane J, et al. Transferring the blues: Depression-associated gut microbiota induces neurobehavioural changes in the rat. J Psychiatr Res. 2016;82:109-18.

143. Liu R, Zhang C, Shi Y, Zhang F, Li L, Wang X, et al. Dysbiosis of gut microbiota associated with clinical parameters in polycystic ovary syndrome. Front Microbiol. 2017:8:1-12.

144. Macut D, Bjekić-Macut J, Rahelić D, Doknić M. Insulin and the polycystic ovary syndrome. Diabetes Res Clin Pract. 2017;130:163-70. 
145. Evans SJ, Bassis CM, Hein R, Assari S, Flowers SA, Kelly MB, et al. The gut microbiome composition associates with bipolar disorder and illness severity. J Psychiatr Res. 2017;87:23-29.

146. Severance EG, Gressitt KL, Stallings CR, Katsafanas E, Schweinfurth LA, Savage $\mathrm{CL}$, et al. Candida albicans exposures, sex specificity and cognitive deficits in schizophrenia and bipolar disorder. npj Schizophr. 2016;2:16018.

147. Jašarević $E$, Morrison KE, Bale TL. Sex differences in the gut microbiome-brain axis across the lifespan. Philos Trans R Soc B Biol Sci. 2016;371:20150122.

148. Moloney GM, O'Leary OF, Salvo-Romero E, Desbonnet L, Shanahan F, Dinan TG, et al. Microbial regulation of hippocampal miRNA expression: Implications for transcription of kynurenine pathway enzymes. Behav Brain Res. 2017;334:50-54.

149. Davis DJ, Hecht PM, Jasarevic E, Beversdorf DQ, Will MJ, Fritsche K, et al. Sexspecific effects of docosahexaenoic acid (DHA) on the microbiome and behavior of socially-isolated mice. Brain Behav Immun. 2017;59:38-48.

150. Yurkovetskiy L, Burrows M, Khan AA, Graham L, Volchkov P, Becker L, et al. Gender bias in autoimmunity is influenced by microbiota. Immunity. 2013;39: 400-12.

151. Bonaccorso S, Marino V, Biondi M, Grimaldi F, Ippoliti F, Maes M. Depression induced by treatment with interferon-alpha in patients affected by hepatitis $C$ virus. J Affect Disord. 2002;72:237-41.

152. Kim J-M, Stewart R, Kim J-W, Kang H-J, Bae K-Y, Kim S-W, et al. Changes in proinflammatory cytokine levels and late-life depression: a two year population based longitudinal study. Psychoneuroendocrinology. 2018;90:85-91.

153. Khandaker GM, Pearson RM, Zammit S, Lewis G, Jones PB. Association of serum interleukin 6 and C-reactive protein in childhood with depression and psychosis in Young Adult Life. JAMA Psychiatry. 2014;71:1121.

154. Raison CL, Rutherford RE, Woolwine BJ, Shuo C, Schettler P, Drake DF, et al. $A$ randomized controlled trial of the tumor necrosis factor antagonist infliximab for treatment-resistant depression: the role of baseline inflammatory biomarkers. Arch Gen Psychiatry. 2013;70:31-41.

155. Dowlati Y, Herrmann N, Swardfager W, Liu H, Sham L, Reim EK, et al. A metaanalysis of cytokines in major depression. Biol Psychiatry. 2010;67:446-57.

156. Gabay C. Interleukin-6 and chronic inflammation. Arthritis Res Ther. 2006:8:S3.

157. Breslau J, Gilman SE, Stein BD, Ruder T, Gmelin T, Miller E. Sex differences in recent first-onset depression in an epidemiological sample of adolescents. Transl Psychiatry. 2017;7:e1139.

158. Deecher D, Andree TH, Sloan D, Schechter LE. From menarche to menopause: exploring the underlying biology of depression in women experiencing hormonal changes. Psychoneuroendocrinology. 2008;33:3-17.

159. Lamason R, Zhao P, Rawat R, Davis A, Hall JC, Chae JJ, et al. Sexual dimorphism in immune response genes as a function of puberty. BMC Immunol. 2006;7:2.

160. Joinson C, Heron J, Lewis G, Croudace T, Araya R. Timing of menarche and depressive symptoms in adolescent girls from a UK cohort. $\mathrm{Br} J$ Psychiatry. 2011;198:17-23.

161. Gouon-Evans V, Lin EY, Pollard JW. Requirement of macrophages and eosinophils and their cytokines/chemokines for mammary gland development. Breast Cancer Res. 2002;4:155-64.

162. Shrier LA, Bowman FP, Lin M, Crowley-nowick PA. Mucosal immunity of the adolescent female genital tract. J Adolesc Heal. 2003;32:183-6.

163. Itman C, Mendis S, Barakat B, Loveland KL. All in the family: TGF- $b$ family action in testis development. Reproduction. 2006;132:233-46.

164. Witkin SS, Jeremias J, Bongiovanni AM, Munoz MG, Immune regulation in the male genital tract. Infect Dis Obstet Gynecol. 1996;4:131-5.

165. Tam CS, Garnett SP, Cowell CT, Heilbronn LK, Lee JW, Wong M, et al. IL-6, IL-8 and IL-10 levels in healthy weight and overweight children. Horm Res Paediatr. 2010;73:128-34.

166. Martos-Moreno GÁ, Barrios V, Argente J. Normative data for adiponectin, resistin, interleukin 6 and leptin/receptor ratio in a healthy Spanish pediatric population: Relationship with sex steroids. Eur J Endocrinol. 2006;155:429-34.

167. Roomruangwong $C$, Anderson G, Berk M, Stoyanov D, Carvalho AF, Maes M (2017a). A neuro-immune, neuro-oxidative and neuro-nitrosative model of prenatal and postpartum depression. Prog Neuropsychopharmacology Biol Psychiatry. 2018;81:262-74.

168. Bränn E, Papadopoulos F, Fransson E, White R, Edvinsson Å, Hellgren C, et al. Inflammatory markers in late pregnancy in association with postpartum depression-a nested case-control study. Psychoneuroendocrinology. 2017;79: 146-59.

169. Leff-Gelman P, Mancilla-Herrera I, Flores-Ramos M, Cruz-Fuentes C, ReyesGrajeda JP, García-Cuétara Mdel P, et al. The immune system and the role of inflammation in perinatal depression. Neurosci Bull. 2016;32:398-420.

170. Roomruangwong C, Barbosa DS, Matsumoto AK, Nogueira A, de S, Kanchanatawan B, Sirivichayakul $S$, et al. Activated neuro-oxidative and neuronitrosative pathways at the end of term are associated with inflammation and physio-somatic and depression symptoms, while predicting outcome characteristics in mother and baby. J Affect Disord. 2017;223:49-58.
171. Simpson W, Steiner M, Coote M, Frey BN. Relationship between inflammatory biomarkers and depressive symptoms during late pregnancy and the early postpartum period: a longitudinal study. Rev Bras Psiquiatr. 2016;38:190-6.

172. Munk-Olsen T, Laursen TM, Mendelson T, Pedersen CB, Mors O, Mortensen PB. Risks and predictors of readmission for a mental disorder during the postpartum period. Arch Gen Psychiatry. 2009:66:189-95.

173. Munk-Olsen T, Laursen TM, Meltzer-Brody S, Mortensen PB, Jones I. Psychiatric disorders with postpartum onset: Possible early manifestations of bipolar affective disorders. Arch Gen Psychiatry. 2012;69:428-34.

174. Bergink V, Laursen TM, Johannsen BMW, Kushner SA, Meltzer-Brody S, MunkOlsen T. Pre-eclampsia and first-onset postpartum psychiatric episodes: a Danish population-based cohort study. Psychol Med. 2015;45:3481-9.

175. Bergink V, Kushner SA, Pop V, Kuijpens $H$, Lambregtse-van den Berg MP, Drexhage $\mathrm{RC}$, et al. Prevalence of autoimmune thyroid dysfunction in postpartum psychosis. Br J Psychiatry. 2011;198:264-8.

176. Kumar MM, Venkataswamy MM, Sathyanarayanan G, Thippeswamy $H$, Chandra PS, Mani RS. Immune system aberrations in postpartum psychosis: an immunophenotyping study from a tertiary care neuropsychiatric hospital in India. J Neuroimmunol. 2017;310:8-13.

177. Bergink V, Burgerhout KM, Weigelt K, Pop VJ, De Wit H, Drexhage RC, et al. Immune system dysregulation in first-onset postpartum psychosis. Biol Psychiatry. 2013;73:1000-7.

178. Posillico CK, Schwarz JM. An investigation into the effects of antenatal stressors on the postpartum neuroimmune profile and depressive-like behaviors Behav Brain Res. 2016;298:218-28.

179. Haim A, Julian D, Albin-Brooks C, Brothers HM, Lenz KM, Leuner B. A survey of neuroimmune changes in pregnant and postpartum female rats. Brain Behav Immun. 2016;59:67-78.

180. O'Mahony SM, Myint A-M, van den Hove D, Desbonnet L, Steinbusch H, Leonard BE. Gestational stress leads to depressive-like behavioural and immunological changes in the rat. Neuroimmunomodulation. 2006;13:82-8.

181. Wharton W, Gleason CE, Olson SR, Carlsson CM, Asthana S. Neurobiological underpinnings of the estrogen - mood relationship. Curr Psychiatr Rev. 2013;8: 247-56.

182. Hu L-Y, Shen C-C, Hung J-H, Chen P-M, Wen C-H, Chiang Y-Y, et al. Risk of psychiatric disorders following symptomatic menopausal transition. Med (Baltim). 2016;95:e2800.

183. Pfeilschifter J, Köditz R, Pfohl M, Schatz H. Changes in proinflammatory cytokine activity after menopause. Endocr Rev. 2002;23:90-119.

184. Vogels RJ, Koenders MA, van Rossum EFC, Spijker AT, Drexhage HA. T cell deficits and overexpression of hepatocyte growth factor in anti-inflammatory circulating monocytes of middle-aged patients with bipolar disorder characterized by a high prevalence of the metabolic syndrome. Front Psychiatry. 2017;8:1-11.

185. Seidman SN. Testosterone deficiency and mood in aging men: pathogenic and therapeutic interactions. World J Biol Psychiatry. 2003;4:14-20.

186. Grinspoon S, Corcoran C, Stanley T, Baaj A, Basgoz N, Klibanski A et al. (2008). Effects of hypogonadism and testosterone HIV-infected men. J Clin Endocrinol Metab. 2000;85:60-65.

187. Chen $\mathrm{CY}$, Lee $\mathrm{CP}$, Chen $\mathrm{Y}$, Jiang JR, Chu CL, Chen CL. The correlation between emotional distress and aging males' symptoms at a psychiatric outpatient clinic: Sexual dysfunction as a distinguishing characteristic between andropause and anxiety/depression in aging men. Clin Interv Aging. 2013;8:635-40.

188. Khosravi S, Ardebili HE, Larijani B, Nedjat S, Nikbakht Nasrabadi A, Ardebili ME, et al. Are andropause symptoms related to depression? Aging Clin Exp Res. 2015;27:813-20.

189. Sato $\mathrm{Y}$, Tanda $\mathrm{H}$, Kato $\mathrm{S}$, Onishi $\mathrm{S}$, Nakajima $\mathrm{H}$, Nanbu $A$, et al. Prevalence of major depressive disorder in self-referred patients in a late onset hypogonadism clinic. Int J Impot Res. 2007;19:407-10.

190. Mor G, Nilsen J, Horvath T, Bechmann I, Brown S, Garcia-Segura LM, et al. Estrogen and microglia: a regulatory system that affects the brain. J Neurobiol. 1999:40:484-96.

191. Hanisch U-K, Kettenmann H. Microglia: active sensor and versatile effector cells in the normal and pathologic brain. Nat Neurosci. 2007;10:1387-94.

192. Banati RB, Gehrmann J, Schubert P, Kreutzberg GW. Cytotoxicity of microglia. Glia. 1993:7:111-8.

193. Nelson LH, Lenz KM. The immune system as a novel regulator of sex differences in brain and behavioral development. J Neurosci Res. 2017;95:447-61.

194. Sawada M, Kondo N, Suzumura A, Marunouchi T. Production of tumor necrosis factor-alpha by microglia and astrocytes in culture. Brain Res. 1989;491:394-7.

195. Schnieder TP, Trencevska I, Rosoklija G, Stankov A, Mann JJ, Smiley J, et al. Microglia of pre-frontal white matter in suicide. J Neuropathol Exp Neurol. 2014;73:880-90.

196. Steiner J, Bielau H, Brisch R, Danos P, Ullrich O, Mawrin C, et al. Immunological aspects in the neurobiology of suicide: elevated microglial density in 
schizophrenia and depression is associated with suicide. J Psychiatr Res. 2008;42:

151-7.

197. Torres-Platas SG, Cruceanu C, Chen GG, Turecki G, Mechawar N. Evidence for increased microglial priming and macrophage recruitment in the dorsal anterior cingulate white matter of depressed suicides. Brain Behav Immun. 2014;42: 50-59.

198. Hawton K, van Heeringen K. Suicide. Lancet. 2009;373:1372-81.

199. Gandal MJ, Haney J, Parikshak N, Leppa V, Horvath S, Geschwind DH. Shared molecular neuropathology across major psychiatric disorders parallels polygenic overlap. bioRxiv. 2016;697:40022.

200. Sandiego CM, Gallezot J-D, Pittman B, Nabulsi N, Lim K, Lin S-F, et al. Imaging robust microglial activation after lipopolysaccharide administration in humans with PET. Proc Natl Acad Sci USA. 2015;112:12468-73.

201. Setiawan E, Wilson AA, Mizrahi R, Rusjan PM, Miler L, Rajkowska G, et al. Role of translocator protein density, a marker of neuroinflammation, in the brain during major depressive episodes. JAMA Psychiatry. 2015;72:268-75.

202. Hannestad J, DellaGioia N, Gallezot JD, Lim K, Nabulsi N, Esterlis I, et al. The neuroinflammation marker translocator protein is not elevated in individuals with mild-to-moderate depression: a [11C]PBR28 PET study. Brain Behav Immun. 2013;33:131-8.

203. Notter T, Meyer U. Microglia and schizophrenia: where next? Mol Psychiatry. 2017;22:788-9.

204. Altshuler LL, Abulseoud OA, Foland-Ross L, Bartzokis G, Chang S, Mintz J, et al. Amygdala astrocyte reduction in subjects with major depressive disorder but not bipolar disorder. Bipolar Disord. 2010;12:541-9.

205. Gosselin RD, Gibney S, O'Malley D, Dinan TG, Cryan JF. Region specific decrease in glial fibrillary acidic protein immunoreactivity in the brain of a rat model of depression. Neuroscience. 2009;159:915-25.

206. Lenz KM, Nugent BM, Haliyur R, McCarthy MM. Microglia are essential to masculinization of brain and behavior. J Neurosci. 2013;33:2761-72.

207. Hanamsagar R, Alter MD, Block CS, Sullivan H, Bolton JL, Bilbo SD. Generation of a microglial developmental index in mice and in humans reveals a sex difference in maturation and immune reactivity. Glia. 2017;6: $1504-20$.

208. Thion MS, Low D, Silvin A, Chen J, Grisel P, Schulte-Schrepping J, et al. Microbiome influences prenatal and adult microglia in a sex-specific manner. Cell. 2017;172:500-7.e16.

209. Bollinger JL, Bergeon Burns CM, Wellman CL. Differential effects of stress on microglial cell activation in male and female medial pre-frontal cortex. Brain Behav Immun. 2016;52:88-97.

210. Schwarz JM, Sholar PW, Bilbo SD. Sex differences in microglial colonization of the developing rat brain. J Neurochem. 2012;120:948-63.

211. Nemeth CL, Reddy R, Bekhbat M, Bailey J, Neigh GN. Microglial activation occurs in the absence of anxiety-like behavior following microembolic stroke in female, but not male, rats. J Neuroinflamm. 2014;11:174.

212. Lehmann ML, Cooper HA, Maric D, Herkenham M. Social defeat induces depressive-like states and microglial activation without involvement of peripheral macrophages. J Neuroinflamm. 2016;13:1-19.

213. Hodes GE, Pfau ML, Leboeuf M, Golden SA, Christoffel DJ, Bregman D, et al. Individual differences in the peripheral immune system promote resilience versus susceptibility to social stress. Proc Natl Acad Sci. 2014;111: 18799-18799.

214. Takahashi A, Zhang H, Zhang S, Grossman Y, Aleyasin H, Flanigan M, et al. Establishment of repeated social defeat stress model in female mice. Soc Neurosci. 2017;7:12838.

215. Iñiguez SD, Flores-Ramirez FJ, Riggs LM, Alipio JB, Garcia I, Hernandez MA et al. Vicarious social defeat stress induces depression-related outcomes in female mice. Biol Psychiatry. 2018;83:9-17.

216. Sial OK, Warren BL, Alcantara LF, Parise EM, Bola CA. Vicarious social defeat stress: bridging the gap between physical and emotional stress. J Neurosci Methods. 2016;258:94-103.

217. Warren BL, Vialou VF, Iñiguez SD, Alcantara LF, Wright KN, Feng J, et al. Neurobiological sequelae of witnessing stressful events in adult mice. Biol Psychiatry. 2013;73:7-14.

218. Finnell JE, Wood SK. Neuroinflammation at the interface of depression and cardiovascular disease: evidence from rodent models of social stress. Neurobiol Stress. 2016:4:1-14.

219. Giannarelli C, Rodriguez DT, Zafar MU, Christoffel D, Alique M, Villa G, et al. Susceptibility to chronic social stress increases plaque progression, vulnerability and platelet activation. Thromb Haemost. 2017;117:816-8.

220. Finnell JE, Lombard CM, Padi AR, Moffitt CM, Wilson LB, Wood CS, et al. Physical versus psychological social stress in male rats reveals distinct cardiovascular, inflammatory and behavioral consequences. PLOS ONE. 2017; 12:1-24.
221. Scheinert RB, Haeri MH, Lehmann ML, Herkenham M. Therapeutic effects of stress-programmed lymphocytes transferred to chronically stressed mice. Prog Neuropsychopharmacol Biol Psychiatry. 2016;70:1-7.

222. Brachman RA, Lehmann ML, Maric $D$, Herkenham $M$. Lymphocytes from chronically stressed mice confer antidepressant-like effects to naive mice. J Neurosci. 2015:35:1530-8.

223. Wang J, Hodes GE, Zhang H, Zhang S, Zhao W, Golden SA et al. Epigenetic modulation of inflammation and synaptic plasticity promotes resilience against stress in mice. Nat Commun. 2018;9:477.

224. Wood SK, Wood CS, Lombard CM, Lee CS, Zhang XY, Finnell JE, et al. Inflammatory factors mediate vulnerability to a social stress-induced depressive-like phenotype in passive Coping Rats. Biol Psychiatry. 2015;78:38-48.

225. Howes OD, McCutcheon R. Inflammation and the neural diathesis-stress hypothesis of schizophrenia: a reconceptualization. Transl Psychiatry. 2017;7: e1024-11.

226. Kiraly DD, Horn SR, Van Dam NT, Costi S, Schwartz JC, Kim-Schulze S, et al. Altered peripheral immune profiles in treatment-resistant depression: response to ketamine and prediction of treatment outcome. Transl Psychiatry. 2017;7: e1065.

227. Munkholm K, Vinberg M, Vedel Kessing L. Cytokines in bipolar disorder: a systematic review and meta-analysis. J Affect Disord. 2013;144:16-27.

228. Ashwood P, Krakowiak P, Hertz-Picciotto I, Hansen R, Pessah I, Van de Water J. Elevated plasma cytokines in autism spectrum disorders provide evidence of immune dysfunction and are associated with impaired behavioral outcome. Brain Behav Immun. 2011;25:40-5.

229. Gilman SE, Cherkerzian S, Buka SL, Hahn J, Hornig M, Goldstein JM. Prenatal immune programming of the sex-dependent risk for major depression. Transl Psychiatry. 2016;6:e822.

230. Simanek AM, Parry A, Dowd JB. Differences in the association between persistent pathogens and mood disorders among young-to middle-aged women and men in the U.S. Brain Behav Immun. 2017:68:56-65.

231. Köhler-Forsberg O, Sylvia L, Deckersbach T, Ostacher MJ, McInnis M, losifescu D et al. Clinically relevant and simple immune system measure is related to symptom burden in bipolar disorder. Acta Neuropsychiatr. 2017;7:1-9.

232. Zheng P, Chen JJ, Zhou CJ, Zeng L, Li KW, Sun L, et al. Identification of sexspecific urinary biomarkers for major depressive disorder by combined application of NMR- and GC-MS-based metabonomics. Transl Psychiatry. 2016;6:e955.

233. Gordon JA,Hen R, The serotonergic system and anxiety. Neuromolecular Med. 2004;5:27-40.

234. Rush AJ, Trivedi MH, Wisniewski SR, Nierenberg AA, Stewart JW, Warden D, et al. Acute and longer-term outcomes in depressed outpatients requiring one or several treatment steps: a STAR*D report. Am J Psychiatry. 2006;163: 1905-17.

235. Baca E, Garcia-Garcia M, Porras-Chavarino A. Gender differences in treatment response to sertraline versus imipramine in patients with nonmelancholic depressive disorders. Prog Neuropsychopharmacol Biol Psychiatry. 2004;28: 57-65.

236. Sramek JJ, Murphy MF, Cutler NR. Sex differences in the psychopharmacological treatment of depression. Dialogogues Clin Neurosci. 2016;18:447-57.

237. Quitkin FM, Stewart JW, McGrath PJ, Taylor BP, Tisminetzky MS, Petkova E, et al. Are there differences between women's and men's antidepressant responses? Am J Psychiatry. 2002;159:1848-54.

238. Morsel AM, Morrens M, Sabbe B. An overview of pharmacotherapy for bipolar I disorder. Expert Opin Pharmacother. 2018;19:203-22.

239. Bobo WV. The diagnosis and management of bipolar I and II disorders: clinical practice update. Mayo Clin Proc. 2017;92:1532-51.

240. Viguera aC, Tondo L, Baldessarini RJ. Sex differences in response to lithium treatment. Am J Psychiatry. 2000;157:1509-11.

241. Geddes JR, Goodwin GM, Rendell J, Morriss R, Alder N, Juszczak E, et al. Lithium plus valproate combination therapy versus monotherapy for relapse prevention in bipolar I disorder (BALANCE): a randomised open-label trial. Lancet. 2010:375:385-95.

242. Johnston AM, Eagles JM. Lithium-associated clinical hypothyroidism. Preval risk Factors Br J Psychiatry. 1999;175:336-9.

243. Saleh LA, Hamza M, El Gayar NH, Abd El-Samad AA, Nasr EA, Masoud SI. Ibuprofen suppresses depressive like behavior induced by BCG inoculation in mice: Role of nitric oxide and prostaglandin. Pharmacol Biochem Behav. 2014;125: 29-39.

244. Warner-Schmidt JL, Vanoverb KE, Chena EY, Marshalla JJ, Greengarda P. Antidepressant effects of selective serotonin reuptake inhibitors (SSRIs) are attenuated by antiinflammatory drugs in mice and humans. Proc Natl Acad Sci. 2011;108:7826-31.

245. Köhler O, Petersen L, Mors O, Gasse C. Inflammation and depression: combined use of selective serotonin reuptake inhibitors and NSAIDs or paracetamol and psychiatric outcomes. Brain Behav. 2015;5:1-12. 
246. Anderson GD. Gender differences in pharmacological response. Int Rev Neurobiol. 2008;83:1-10.

247. Miners J, Attwood J, Birkett D. Influence paracetamol. Br J Clin Pharmac. 1983;16:503-9.

248. Franconi F, Brunelleschi S, Steardo L, Cuomo V. Gender differences in drug responses. Pharmacol Res. 2007;55:81-95.

249. Li N, Lee B, Liu R-J, Banasr M, Dwyer JM, Iwata M, et al. mTOR-dependent synapse formation underlies the rapid antidepressant effects of NMDA antagonists. Science. 2010;329:959-64.

250. Tan S, Wang Y, Chen K, Long Z, Zou J. Ketamine alleviates depressive-like behaviors via down-regulating inflammatory cytokines induced by chronic restraint stress in mice. Biol Pharm Bull. 2017;40:1260-7.

251. Wang N, Yu H-Y, Shen X-F, Gao Z-Q, Yang C, Yang J-J, et al. The rapid antidepressant effect of ketamine in rats is associated with down-regulation of pro-inflammatory cytokines in the hippocampus. Ups J Med Sci. 2015;120: 241-8.

252. Li $Y$, Shen $R$, Wen $G$, Ding $R$, Du $A$, Zhou J, et al. Effects of ketamine on levels of inflammatory cytokines IL-6, IL-1 $\beta$, and TNF- $\alpha$ in the hippocampus of mice following acute or chronic administration. Front Pharmacol. 2017;8:1-14.

253. Yang Y, Cui Y, Sang K, Dong Y, Ni Z, Ma S, et al. Ketamine blocks bursting in the lateral habenula to rapidly relieve depression. Nature. 2018;554:317-22.

254. Cui Y, Yang Y, Ni Z, Dong Y, Cai G, Foncelle A, et al. Astroglial Kir4.1 in the lateral habenula drives neuronal bursts in depression. Nature. 2018;554:323-7.

255. Franceschelli A, Sens J, Herchick S, Thelen C, Pitychoutis PM. Sex differences in the rapid and the sustained antidepressant-like effects of ketamine in stressnaïve and "depressed" mice exposed to chronic mild stress. Neuroscience. 2015;290:49-60.

256. Sarkar A, Kabbaj M. Sex differences in effects of ketamine on behavior, spine density and synaptic proteins in socially isolated rats. Biol Psychiatry. 2016;80: 448-56.

257. Carrier N, Kabbaj M. Sex differences in the antidepressant-like effects of ketamine. Neuropharmacology. 2013;70:27-34.

258. Dossat AM, Wright KN, Strong CE, Kabbaj M. Behavioral and biochemical sensitivity to low doses of ketamine: Influence of estrous cycle in C57BL/6 mice. Neuropharmacology. 2018;130:30-41.

259. Duman RS, Aghajanian GK, Sanacora G, Krystal JH. Synaptic plasticity and depression: new insights from stress and rapid-acting antidepressants. Nat Med. 2016;22:238-49.

260. Kappelmann N, Lewis G, Dantzer R, Jones PB, Khandaker GM. Antidepressant activity of anti-cytokine treatment: a systematic review and meta-analysis of clinical trials of chronic inflammatory conditions. Mol Psychiatry. 2016;23: 335-43.

261. Sun Y, Wang D, Salvadore G, Hsu B, Curran M, Casper C, et al. The effects of interleukin-6 neutralizing antibodies on symptoms of depressed mood and anhedonia in patients with rheumatoid arthritis and multicentric Castleman's disease. Brain Behav Immun. 2017;66:156-64.

262. Miyamoto N, Mochizuki S, Fujii S, Yoshida K, Sakurai K. Adjuvant activity enhanced by cross-linked cpg-oligonucleotides in $\beta$-glucan nanogel and its antitumor effect. Bioconjug Chem. 2017;28:565-73.
263. Uemura Y, Naoi T, Kanai Y, Kobayashi K. The efficiency of lipid nanoparticles with an original cationic lipid as a siRNA delivery system for macrophages and dendritic cells. Pharm Dev Technol. 2018; https://doi.org/10.1080/ 10837450.2018.1469149.

264. Farina M, Alexander JF, Thekkedath U, Ferrari M, Grattoni A. Cell encapsulation: overcoming barriers in cell transplantation in diabetes and beyond. Adv Drug Deliv Rev. 2018; https://doi.org/10.1016/j.addr.2018.04.018.

265. Lanquillon S, Krieg J-C, Bening-Abu-Shach U, Vedder H. Cytokine production and treatment response in major depressive disorder. Neuropsychopharmacology. 2000;22:370-9.

266. Birur B, Amrock EM, Shelton RC, Li L. Sex differences in the peripheral immune system in patients with depression. Front Psychiatry. 2017;8:1-7.

267. Pallavi $P$, Sagar R, Mehta M, Sharma S, Subramanium A, Shamshi F, et al. Serum cytokines and anxiety in adolescent depression patients: gender effect. Psychiatry Res. 2015;229:374-80.

268. Maes M, Scharpé S, Meltzer HY, Bosmans E, Suy E, Calabrese J, et al. Relationships between interleukin- 6 activity, acute phase proteins, and function of the hypothalamic-pituitary-adrenal axis in severe depression. Psychiatry Res. 1993:49:11-27.

269. Valkanova V, Ebmeier KP, Allan CL. CRP, IL-6 and depression: a systematic review and meta-analysis of longitudinal studies. J Affect Disord. 2013;150:736-44.

270. Himmerich $H$, Fulda $S$, Linseisen J, Seiler H, Wolfram G, Himmerich $S$, et al Depression, comorbidities and the TNF-a system. Eur Psychiatry. 2008;23:421-9.

271. Domenici E, Wille DR, Tozzi F, Prokopenko I, Miller S, McKeown A et al. Plasma protein biomarkers for depression and schizophrenia by multi analyte profiling of case-control collections. PLoS ONE. 2010;5:e9166.

272. Maes M, Lambrechts J, Suy E, Vandervorst C, Bosmans E. Absolute number and percentage of circulating natural killer, non-mhc-restricted t cytotoxic, and phagocytic cells in unipolar depression. Neuropsychobiology. 1994;29:157-63.

273. Dickerson F, Stallings C, Origoni A, Boronow J, Yolken R. Elevated serum levels of C-reactive protein are associated with mania symptoms in outpatients with bipolar disorder. Prog Neuropsychopharmacol Biol Psychiatry. 2007;31:952-5.

274. Goldstein $\mathrm{BI}$, Collinger KA, Lotrich F, Marsland AL, Gill M-K, Axelson DA, et al. Preliminary findings regarding proinflammatory markers and brain-derived neurotrophic factor among adolescents with bipolar spectrum disorders. J Child Adolesc Psychopharmacol. 2011;21:479-84.

275. Luo $\mathrm{Y}$, He H, Zhang M, Huang $X$, Fan N. Altered serum levels of TNF-a, IL-6 and IL-18 in manic, depressive, mixed state of bipolar disorder patients. Psychiatry Res. 2016;244:19-23.

276. Gill J, Vythilingam M, Page GG, Manuscript A, Cortisol L. Low cortisol, high DHEA and high levels of stimulated TNF-alpha, and IL- 6 in women with PTSD. J Trauma Inj Infect Crit Care. 2008:21:530-9.

277. Hoge EA, Brandstetter K, Moshier S, Pollack MH, Wong KK, Simon NM. Broad spectrum of cytokine abnormalities in Panic disorder and Posttraumatic stress disorder. Depress Anxiety. 2009;26:447-55.

278. Gill J, Luckenbaugh D, Charney D, Vythilingam M. Sustained elevation of serum interleukin- 6 and relative insensitivity to hydrocortisone differentiates posttraumatic stress disorder with and without depression. Biol Psychiatry. 2010;68: 999-1006. 